\title{
Age-related diseases as vicious cycles
}

\author{
Aleksey V. Belikov \\ Independent researcher, Moscow, Russia \\ Correspondence to: belikov.research@gmail.com
}

Age-related diseases (ARDs) are the leading cause of death worldwide, and contribute to $90 \%$ of mortality in developed countries. Interestingly, the mortality rates of individual ARDs increase exponentially with age. Processes described by the exponential growth function typically involve a branching chain reaction or, more generally, a positive feedback loop. Here I propose that each ARD is mediated by one or several positive feedback loops (vicious cycles). I then identify critical vicious cycles in five major ARDs: atherosclerosis, hypertension, diabetes, Alzheimer's and Parkinson's. I also propose that the progression of ARDs can be halted by selectively interrupting the vicious cycles and suggest the most promising targets. An evolutionary perspective is also offered.

Keywords: aging, age-related disease, mortality rate, positive feedback loop, vicious cycle

$\mathrm{N}$ ationwide mortality and disease incidence statistics are perhaps the most powerful and least biased datasets on human diseases that we currently have. These data are derived from humans living in the complex environment and developing diseases naturally, and not from distantly related animals contained in laboratory conditions under disease-inducing regimens. Whilst clinical studies share the same advantages, the number of human subjects is orders of magnitude lower, and a bias related to study design is always present.

By studying the incidence statistics of 20 most prevalent cancer types in relation to patients' age, I have previously shown that it closely follows the probability density function of the Erlang distribution". The Erlang distribution describes the probability of several independent random events occurring by the given time, but not earlier or later. This fits well with the widely accepted multiple-hit hypothesis of carcinogenesis, which states that cancers arise after several successive events ${ }^{2-4}$. Whilst no consensus has been reached on the nature of these events, driver mutations are the most probable candidate. Such mutations confer the growth advantage, apoptosis resistance or other oncogenic properties to the cell, as opposed to inconsequential passenger mutations ${ }^{5}$. Overall, these results suggest that cancer is essentially a random event and not the true gradually developing ARD.

I have then decided to use disease statistics to elucidate the underlying nature of five major ARDs: atherosclerosis, hypertension, diabetes, Alzheimer's and Parkinson's. As large-scale incidence data for these diseases is not readily available, I have instead evaluated the age distribution of mortality (see Methods for details). Unlike incidence rates, mortality rates represent the hazard function derived from the probability density function. They are usually approximated by the hazard function of the Gompertz distribution, which is essentially the exponential function. However, the exponential function does not have an upper limit, whereas the mortality rate does $(100,000$ deaths per 100,000 people), so it cannot be the mathematically correct choice. Instead, the logistic function, which initially behaves like the exponential but then asymptotically approaches the upper limit, appears more appropriate and indeed provides an excellent fit to the data (Figure 1). 

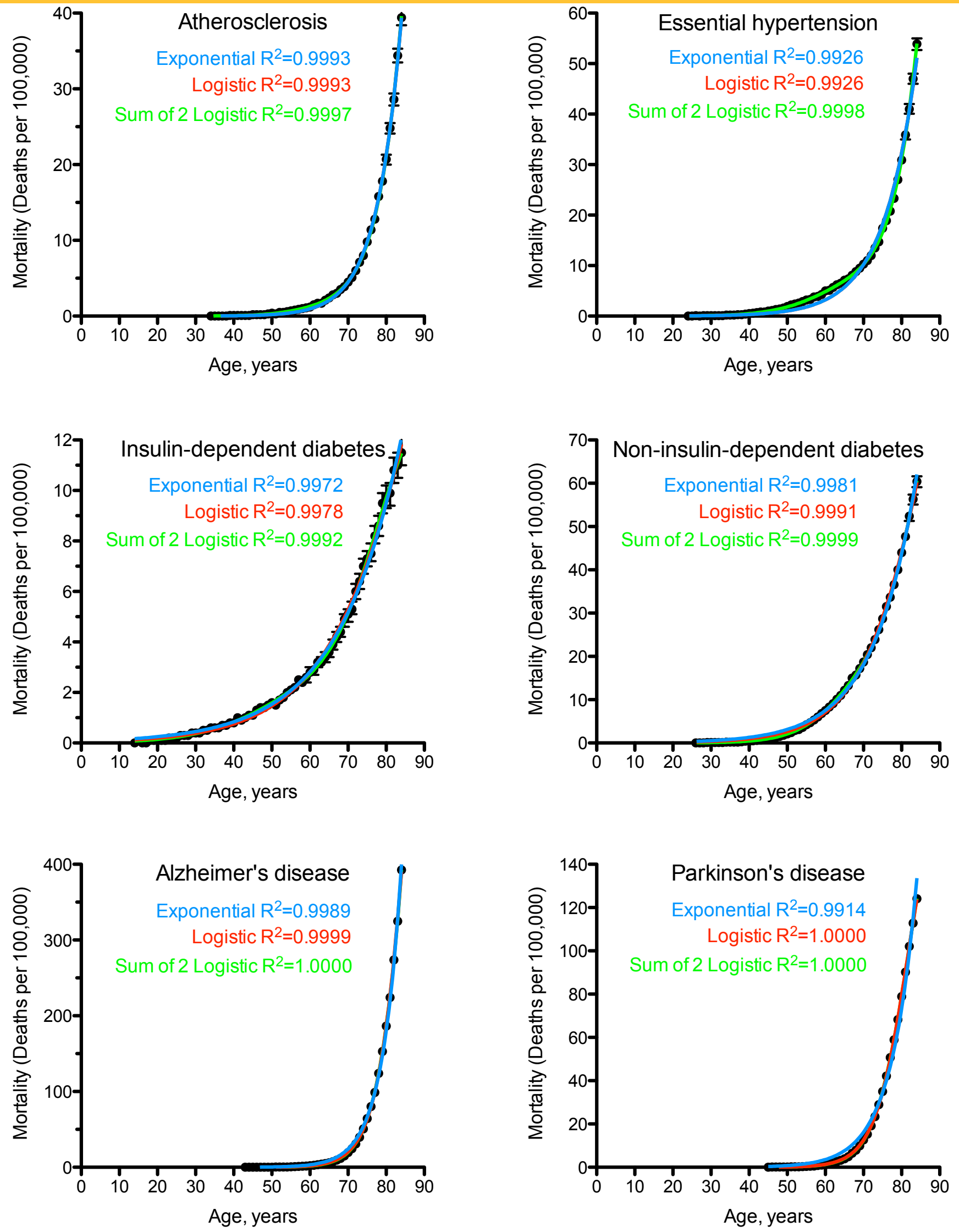

Figure 1. The logistic function is preferable over the exponential function (Gompertz hazard rate) for the approximation of the age distributions of mortality rates for age-related diseases. Dots indicate actual data for one-year age intervals. Curves indicate the exponential (blue), logistic (red) and the sum of two logistic (green) functions fit to the data. A simpler model is plotted on top of a more complex model (exponential > logistic > sum of 2 logistic). 
It can be seen that the exponential function provides a reasonable approximation for mortality from atherosclerosis, diabetes and Alzheimer's, but is inadequate for mortality from essential hypertension and Parkinson's. The slightly more complex but mathematically correct logistic function provides the fits that are at least as good as for the exponential function, and in addition provides the perfect fit for Parkinson's disease mortality. Finally, the sum of two logistic functions is required for the adequate fit to mortality from essential hypertension. This may indicate that essential hypertension is a heterogeneous disease composed of two major subtypes with different mortality kinetics. Indeed, essential hypertension is defined as hypertension with an unknown cause. It has to be noted that hazard functions of common statistical distributions, including Weibull and gamma, as well as the sum of two exponential functions, failed to provide fits as good as logistic function.

As mentioned above, the logistic function describes exponential growth that slows down when some limiting factors start to play a role. Processes that exhibit an exponential growth behavior are common in natural and artificial systems. They include, but are not limited to, nuclear chain reactions, exothermal heataccelerated chemical reactions, crystallization of water into ice, avalanches, growth of bacteria, growth of prey population after removal of predators, viral epidemics, as well as the acoustic feedback in microphoneamplifier-loudspeaker systems. All these processes involve either a branching chain reaction or, more generally, a positive feedback loop. In lay terms, they can be described as "A produces more of $B$, and $B$ produces more of $A^{\prime \prime}$, with possible intermediates $C, D, E, F$, etc., or in the simplest case, "A produces more of $A$ ".

The well-known property of systems containing positive feedback loops is the progressive amplification of initially small disturbances that leads to system instability and, eventually, destruction, if no negative feedback loops are in place. The vivid examples include nuclear and chemical explosions. I propose that age-related diseases are initiated by relatively small disturbances that are amplified through positive feedback loops (vicious cycles) and lead to the destabilization of organism physiology and, eventually, to death. In the following sections, I will describe specific vicious cycles likely underlying five major ARDs: atherosclerosis, hypertension, diabetes, Alzheimer's and Parkinson's. Potential ways to interrupt these cycles will also be suggested. Finally, I will propose an evolutionary explanation for the existence of these vicious cycles.

\section{The vicious cycle of atherosclerosis}

Cardiovascular diseases are the leading cause of death worldwide. Atherosclerosis and hypertension are the major factors responsible for the myocardial infarction (heart attack) and the cerebrovascular insult (stroke). These events typically occur upon the rupture of a vulnerable atherosclerotic plaque in the artery wall, leading to thrombosis of a coronary artery or an artery in the brain. Vulnerable plaques are defined primarily by the large lipid-rich necrotic core and thin fibrous cap ${ }^{6}$. They progressively develop from initial benign fatty streaks, which are present already in infancy ${ }^{7-9}$. Notably, the number of advanced lesions and the lesion size grow exponentially with age $e^{7,9}$, whereas the fibrous cap thins ${ }^{10,11}$.

I propose the following mechanism involved in the development of a necrotic lipid core (for a similar idea, see $\operatorname{Ref}^{12}$ ):

(1) Low-density lipoprotein

(LDL) concentrations in the bloodstream and in the subendothelial space (intima) of arteries are in dynamic equilibrium ${ }^{13}$ and do not substantially change with age ${ }^{14}$ 
(2) Endothelial cells and vascular smooth muscle cells produce reactive oxygen species (ROS) via NADPH oxidases (NOX), which are required for normal intercellular signaling ${ }^{15,16}$

(3) Occasionally, some LDL in the intima becomes oxidized by ROS from NOX, forming oxLDL $^{17}$

(4) oxLDL promotes the expression of adhesion molecules on endothelial cells that mediate recruitment of monocytes from the bloodstream ${ }^{8,18-22}$

(5) Recruited monocytes differentiate into macrophages that engulf oxLDL (mainly via the scavenger receptor CD36) and try to digest it ${ }^{23-26}$

(6) Phagocytosis of macrophages is accompanied by the release of large amounts of ROS via NOX-2 (the so called respiratory burst) 27,28

(7) These ROS oxidize more $\mathrm{LDL}^{12,29}$

Steps 4 to 7 are repeated many times: the key vicious cycle is formed (Figure 2A). It is supplemented by additional cytokinemediated positive feedback loops: oxLDLactivated macrophages release cytokines that enhance macrophage recruitment, oxLDL phagocytosis, ROS production and cytokine production, either directly or via the activation of $T$ cells, endothelial cells and vascular smooth muscle cells ${ }^{30,31}$. Eventually, the amount of oxLDL generated by the congregation of ROS-producing macrophages exceeds their digestion capacity ${ }^{32}$. Macrophages turn into foam cells and die, leading to necrotic core growth ${ }^{33}$. Fibrous cap thinning is likely the byproduct of the vicious cycle of lipid core growth. Indeed, thinning occurs due to the destruction of extracellular matrix collagens and elastins by matrix metalloproteinases $(\mathrm{MMPs})^{34}$, which are secreted by macrophages that are recruited to the lipid core ${ }^{35}$ (Figure 2A).

In the end, it is not very important what exactly initiates this feedback loop - an increase in the intimal concentration of LDL, e.g. due to excessive fatty meal intake, or the burst of ROS production by endothelial cells, e.g. due to angiotensin II stimulation, or both factors. After all, fatty streaks are present already in the human fetus ${ }^{8}$. Once the loop is formed, it becomes self-sustainable, so no repeated external influences are required to keep it functioning. The only possible way to prevent the progression of the disease is to interrupt the vicious cycle, at any of its steps.

For example, ROS can be scavenged with antioxidants, decreasing oxLDL formation; the expression of adhesion molecules on endothelial cells can be downregulated, interfering with monocyte recruitment; CD36 and NOX-2 expression or function in macrophages can be inhibited, abolishing oxLDL uptake and ROS production; the secretion of cytokines and MMPs by macrophages can also be reduced to prevent additional feedback loops and fibrous cap degradation. However, ROS, adhesion molecules, macrophages, CD36, NOX-2, cytokines and MMPs also serve many physiological functions in the arterial wall and elsewhere, so their complete elimination or inhibition will do more harm than good. This may explain the failure of traditional approaches based on antioxidants and inhibitors. Instead, the success can be achieved when these same targets will be hit selectively in the atherosclerotic plaque. This approach will likely be based on the delivery of inhibitor cocktails within nanoparticles guided by plaque-specific markers ${ }^{36-38}$.

\section{The vicious cycles of hypertension}

As mentioned in the previous section, hypertension (high blood pressure) is one of the two leading causes of acute cardiovascular events, along with atherosclerosis. For example, the rupture of a vulnerable plaque or of an aneurism is more likely to occur when blood pressure is high. Also, hypertension imposes greater load on the heart muscle, which may lead to the congestive heart failure. 
Peer-reviewed version available at Aging Research Reviews 2019, 49, 11-26; doi:10.1016/i.arr.2018.11.002

\section{A}

LDL in the blood
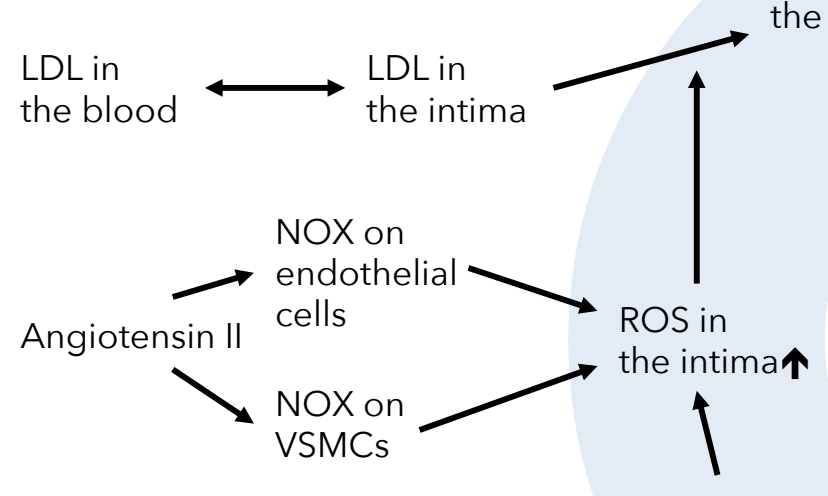

Cap $\downarrow \longleftarrow$ Collagen $\downarrow$

$\underset{\text { core } \uparrow}{\text { Necrotic }} \longleftarrow \underset{\text { cells } \uparrow}{\text { Foam }} \longleftarrow \begin{aligned} & \text { oxLDL } \\ & \text { overload } \uparrow\end{aligned}$

\section{B}
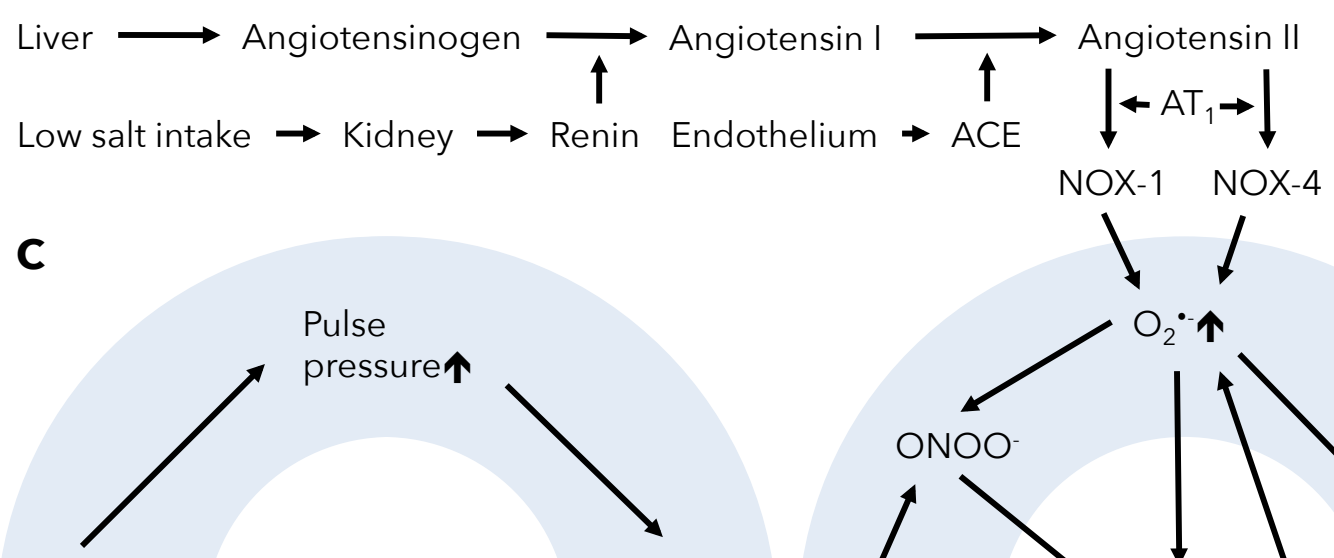

Lase artey stiffess?

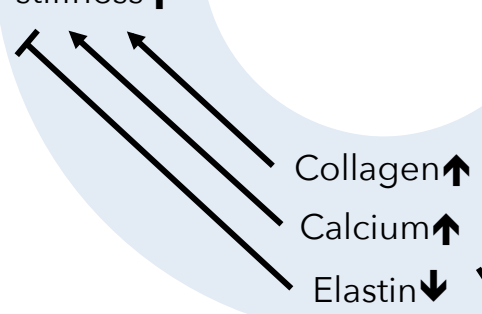

Elastin $\downarrow$

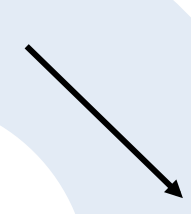

VSMC phenotype switching $\uparrow$

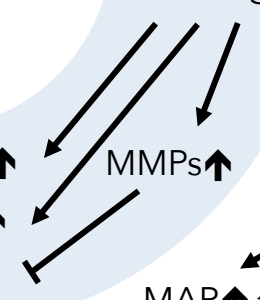

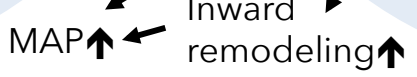
molecules on endothelial

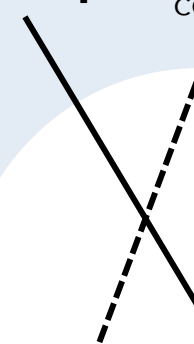

1 $\mathrm{O}_{2} \cdot \uparrow$
Monocytes

in the blood

Adhesion the intima cells $\uparrow$
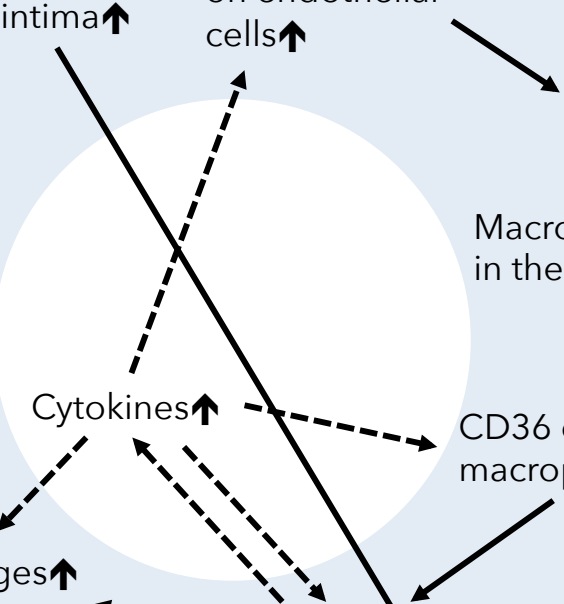

Macrophages in the intima $\uparrow$

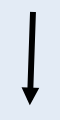

CD36 on macrophages $\uparrow$

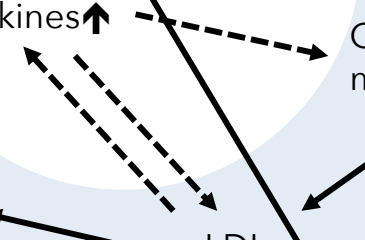

phagocytosis $\uparrow$

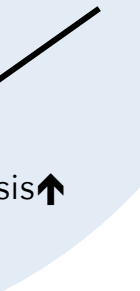

Figure 2. The vicious cycles of atherosclerosis (A), increased mean arterial pressure (B) and increased pulse pressure (C). Short vertical arrows indicate increase $(\boldsymbol{\uparrow})$ or decrease $(\boldsymbol{\Downarrow})$ in parameters that are likely to change exponentially or logistically with age. LDL - low density lipoprotein, oxLDL - oxidized LDL, MMPs - matrix metalloproteinases, NOX - NADPH oxidase, ROS - reactive oxygen species, VSMCs - vascular smooth muscle cells, ACE - angiotensin converting enzyme, $\mathrm{AT}_{1}$ - angiotensin II receptor type $1, \mathrm{O}_{2}{ }^{-{ }^{-}}$- superoxide, SOD - superoxide dismutase, eNOS - endothelial nitric oxide synthase, $\mathrm{NO}$ - nitric oxide, $\mathrm{ONOO}^{-}$- peroxynitrite, $\mathrm{BH}_{4}$ tetrahydrobiopterin, $\mathrm{oxBH}_{4}$ - oxidized $\mathrm{BH}_{4}, \mathrm{MAP}$ - mean arterial pressure. 
Hypertension can be subdivided into two types: increased mean arterial pressure and increased pulse pressure. Mean arterial pressure increases until age 60, when it reaches a plateau, whereas pulse pressure increases exponentially until the oldest observed age ${ }^{39}$. Thus, these two types of hypertension likely correspond to the two subtypes of hypertension mortality discussed in the introduction. Indeed, the contribution of the minor mortality component to overall mortality from hypertension starts to decrease at age 60 (Figure 1).

An increase in mean arterial pressure occurs upon an increase in cardiac output and/or total peripheral (systemic) vascular resistance ${ }^{40,41}$. The former is often responsible for prehypertension, whereas the latter mediates the established form of the disease ${ }^{42-44}$. Systemic vascular resistance is determined predominantly by the lumen diameter of small arteries and arterioles, also called resistance vessels ${ }^{40}$. Increased vascular resistance can thus be due to increased vasoconstriction or impaired vasodilation.

The constriction of blood vessels can be caused by angiotensin II released by the reninangiotensin-aldosterone system, mostly in response to decreased salt reabsorption in the kidneys and the related loss of blood volume ${ }^{45,46}$. However, the activity of the reninangiotensin-aldosterone system does not increase with age, but rather decreases, both in hypertensives and in controls ${ }^{42,47-49}$. The hyperactivity of the sympathetic nervous system can also result in marked vasoconstriction ${ }^{50,51}$. Interestingly, the sympathetic activity correlates positively with mean arterial pressure ${ }^{52,53}$ and age $^{54}$. However, the complexity of the central nervous system and our insufficient knowledge of it hinder the identification of potential vicious cycles. The relaxation of blood vessels is achieved chiefly by nitric oxide (NO), which is produced by endothelial nitric oxide synthase (eNOS) primarily in response to shear stress ${ }^{\mathrm{s}}$. Reduced $\mathrm{NO}$ availability, endothelial dysfunction and impaired vasodilation are commonly implicated in essential hypertension ${ }^{56-58}$.

I propose the following chain of events underlying the reduced $\mathrm{NO}$ availability (a similar concept has been suggested before ${ }^{59}$ ):

(1) Low salt intake activates the reninangiotensin-aldosterone system, which releases angiotensin $\|^{60,61}$

(2) Angiotensin II activates its receptor $\left(A T_{1}\right)$ on endothelial and vascular smooth muscle cells ${ }^{62}$

(3) $A T_{1}$ triggering leads to the increased expression and activation of NOX-1 and NOX4 that start to produce superoxide $\left(\mathrm{O}_{2}{ }^{*}\right)^{63-66}$

(4) Some $\mathrm{O}_{2}{ }^{--}$dismutates to hydrogen peroxide $\left(\mathrm{H}_{2} \mathrm{O}_{2}\right)$, either spontaneously or with the help of superoxide dismutase (SOD) ${ }^{67}$

(5) $\mathrm{H}_{2} \mathrm{O}_{2}$ promotes the activation of eNOS, which increases the synthesis of $\mathrm{NO}^{68}$

(6) Some $\mathrm{O}_{2}{ }^{*-}$ reacts with $\mathrm{NO}$, producing peroxynitrite $\left(\mathrm{ONOO}^{-}\right)^{69}$

(7) Both $\mathrm{O}_{2} \cdot-70$ and $\mathrm{ONOO}^{-71}$ oxidize and inactivate eNOS cofactor tetrahydrobiopterin $\left(\mathrm{BH}_{4}\right)$

(8) When the ratio of intact $\mathrm{BH}_{4}$ to oxidized $\mathrm{BH}_{4}$ derivatives decreases, eNOS undergoes uncoupling and switches from the production of $\mathrm{NO}$ to the production of $\mathrm{O}_{2}^{\cdot-59,72,73}$

Steps 4 to 8 comprise the vicious cycle (Figure 2B). After some time, $\mathrm{BH}_{4}$ becomes severely oxidized, most eNOS enzymes switch to producing $\mathrm{O}_{2}{ }^{\circ}$, NO synthesis dramatically reduces, and NO availability approaches zero. These events impair the relaxation of small arteries and arterioles, increase systemic vascular resistance, and ultimately raise mean arterial pressure to the observed plateau. Moreover, prolonged functional vasoconstriction causes inward eutrophic remodeling of small arteries, leading to the structural fixation of the abnormality ${ }^{74}$. Importantly, inward eutrophic remodeling can be induced by the chronic inhibition of $\mathrm{NO}$ production $^{75}$. Fortunately, vasodilator agents 
have been shown to reverse this process by inducing outward remodeling ${ }^{76}$. Interestingly, the same vicious cycle may be present in large arteries where it may be interwoven with the atherosclerosis cycle, as both cycles generate, and are propelled by, increasing ROS levels.

Most effective strategies to interrupt this vicious cycle would be using the scavengers of $\mathrm{O}_{2}^{-77}$ and $\mathrm{ONOO}^{-78}$ and increasing SOD expression and $\mathrm{BH}_{4}$ synthesis ${ }^{79}$ in endothelial and vascular smooth muscle cells, whereas exogenous supplementation of $\mathrm{BH}_{4}$ is ineffective due to its rapid oxidation and slow reduction ${ }^{80,81}$. Inhibiting vascular NADPH oxidases, $A T_{1}$ or angiotensin II synthesis also appears much less effective, as once the positive feedback loop (steps 4-8) is initiated, these molecules are no longer critical for the progression of the disease.

Pulse pressure is determined predominantly by the elasticity (or stiffness) of large arteries ${ }^{40,41}$. Arterial stiffening causes increased pulse pressure by attenuating the compensatory arterial stretching during systole and shrinking during diastole ${ }^{82}$. Arterial stiffening progresses exponentially ${ }^{83}$ and appears to predict hypertension ${ }^{84-89}$ and acute cardiovascular events ${ }^{90}$. Interestingly, pulse pressure ${ }^{91}$ and systolic pressure ${ }^{83}$ also predict arterial stiffening, suggesting the possibility of a positive feedback loop between hypertension and arterial stiffening ${ }^{39,92-94}$. Arterial stiffening results from the fragmentation of elastin, deposition of collagen and calcium, as well as elastin and collagen crosslinking ${ }^{95,96}$. It is not known how exactly hypertension triggers these processes, but the transformation of vascular smooth muscle cells in the arterial wall to the synthetic and osteoblastic phenotypes in response to mechanical forces is the likely candidate 97,98 (Figure 2C). Thus, further research into the vascular smooth muscle cell phenotype switching will help to uncover the ways to interfere with or even reverse this pathological remodeling of large arteries.

\section{The vicious cycles of diabetes}

Diabetes mellitus is the group of metabolic diseases characterized by increased blood glucose levels (hyperglycemia). There are two major types of diabetes. Type 1 (insulindependent) diabetes is caused mainly by the autoimmune destruction of insulin-producing beta cells in the islets of Langerhans in the pancreas and accounts for 5-10\% of all cases $^{99-101}$. Type 2 (non-insulin-dependent) diabetes also involves the dysfunction and death of beta cells, but is triggered primarily by insulin resistance and comprises $90 \%$ of cases $^{102,103}$. Diabetes may lead to serious health complications, such as neuropathy, retinopathy, nephropathy, seizures, nonketotic hyperosmolar coma, blindness, muscle wasting, chronic kidney disease, ketoacidosis, foot ulcers, cardiovascular diseases, and finally death.

The events underlying the development of type 1 diabetes are typical for a $\mathrm{T}$ cellmediated autoimmune disease ${ }^{104}$ and can be described as follows:

(1) The infection of beta cells by a virus leads to their destruction and the subsequent capture of their self-antigens by antigenpresenting cells, which include macrophages and dendritic cells ${ }^{105,106}$; alternatively, viral or bacterial antigens that mimic beta-cell antigens are captured by antigen-presenting cells elsewhere in the body ${ }^{107-109}$

(2) Antigen-presenting cells migrate to lymph nodes and present captured antigens on Major histocompatibility complex class II (MHC II) in the form of short peptides ${ }^{110}$

(3) Naïve $C D 4^{+} T$ cells with $T$-cell receptor (TCR) complementary to the presented peptide-MHC II complex become activated, license antigen-presenting cells, proliferate, exit the lymph node and migrate to the pancreas $^{110,111}$

(4) Licensed antigen-presenting cells activate naïve autoreactive $\mathrm{CD}^{+} \mathrm{T}$ cells by antigens cross-presented on $\mathrm{MHC} \mathrm{I}$, inducing 
their proliferation and migration to the pancreas ${ }^{111-113}$

(5) In the pancreas, CD4 ${ }^{+} \mathrm{T}$ cells are restimulated by resident antigen-presenting cells via peptide-MHC II and start to secrete cytokines, which stimulate $\mathrm{CD}^{+}{ }^{+} \mathrm{T}$ cells, CD8 ${ }^{+}$ $T$ cells and antigen-presenting cells ${ }^{114,115}$

(6) Activated $\mathrm{CD}^{+} \mathrm{T}$ cells recognize selfantigens in complex with $\mathrm{MHC}$ I on beta cells and destroy these cells with FasL, perforins and granzymes ${ }^{116,117}$

(7) Antigen-presenting cells capture betacell debris that contain novel antigens and epitopes $^{118,119}$

Steps 2 to 7 form the vicious cycle, leading to epitope spreading ${ }^{120,121}$ and the progressive destruction of beta cells (Figure 3A). The avidity maturation of $\mathrm{T}$-cell clones may also be involved in the escalating kinetics of the disease ${ }^{122}$. The loss of beta cells leads to acceleratingly decreasing glucose sensitivity, resulting in exponentially increasing blood glucose and the onset of diabetes ${ }^{123,124}$. Treatment for type 1 diabetes clearly should be directed against the escalation of autoimmune response in the pancreas. The selective elimination ${ }^{125,126}$ or suppression ${ }^{127}$ of cytotoxic and helper $\mathrm{T}$ cells bearing receptors against beta-cell antigens appears to be the most promising approach.

To explain the progressive development of type 2 diabetes, I propose the following sequence of events (see $\operatorname{Ref}^{128}$ for a similar concept):

(1) Overeating (the consumption of more calories than spent) leads to obesity

(2) Obesity causes insulin resistance, likely through the dysfunction ${ }^{129,130}$ and/or inflammation ${ }^{131-136}$ of the adipose tissue. However, insulin resistance does not directly participate in the main vicious cycle of diabetes, because it appears early, when blood glucose levels are still normal, and then changes little, when glucose concentrations in the blood rise exponentially, and beta-cell function dramatically deteriorates ${ }^{137-141}$
(3) Nevertheless, insulin resistance places increased demand on pancreatic beta cells, as they need to produce more insulin to keep blood glucose levels within the normal range ${ }^{142-144}$

(4) An increase in the secretion of insulin per beta cell leads to an increase in the endoplasmic reticulum stress ${ }^{145}$ and apoptosis $^{146-150}$ of beta cells

(5) A decrease in the number of functional beta cells leads to a decrease in the total pancreatic rate of insulin secretion relative to a given glucose level (decreased glucose sensitivity, $\Delta \mathrm{l} / \Delta \mathrm{G}, \mathrm{HOMA}-\mathrm{B})^{138,140,151}$, assuming that the glucose sensitivity of each individual beta cell does not change

(6) A decrease in the total relative insulin secretion rate leads to a decrease in the insulin-mediated glucose uptake by liver, muscle and adipose tissues and a decrease in the insulin-mediated suppression of hepatic glucose production (both also relative to glucose levels in blood) ${ }^{152-154}$, thus increasing blood glucose levels

(7) Moreover, a decrease in the ratio of beta to alpha cells ${ }^{147,148,150}$ (due to beta-cell apoptosis) leads to a decrease in the suppression of glucagon secretion ${ }^{155-157}$, promoting an increase in hepatic glucose production $^{158}$ and a further increase in glucose levels

(8) An increase in blood glucose levels causes each beta cell to secrete more insulin $^{159}$

Steps 4 to 8 form the vicious cycle, leading to impaired glucose tolerance and type 2 diabetes (Figure 3B). It should be noted that the same vicious cycle can be operating in type 1 diabetes in parallel with the autoimmune destruction cycle, as the number of beta cells and glucose sensitivity decrease, and endoplasmic reticulum stress increases, in both cases ${ }^{123,160,161}$. In fact, both diseases might differ only by the factor (autoimmune response vs. insulin resistance) that triggers the vicious cycle. 
A

Lytic viral infection of beta cells
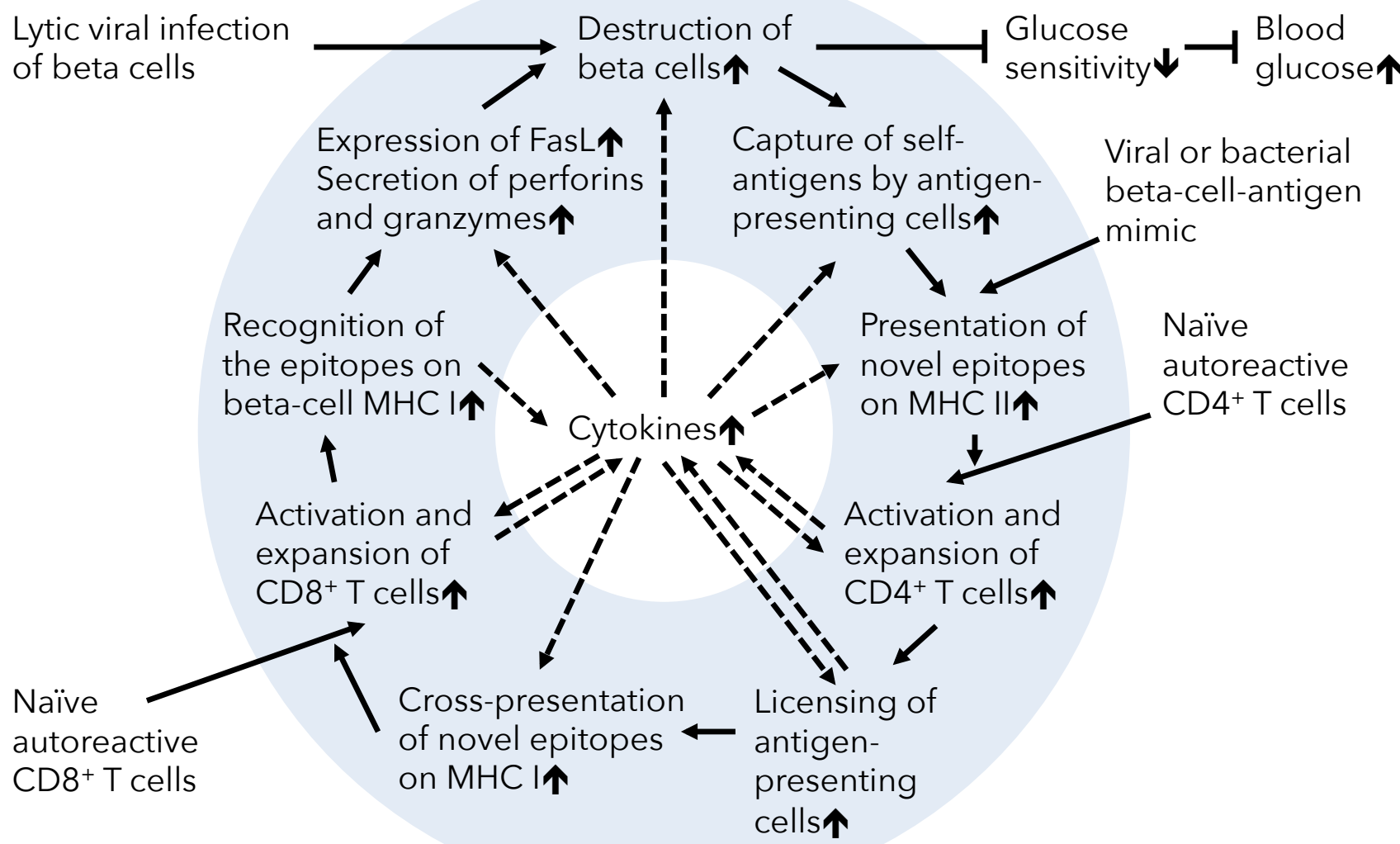

B

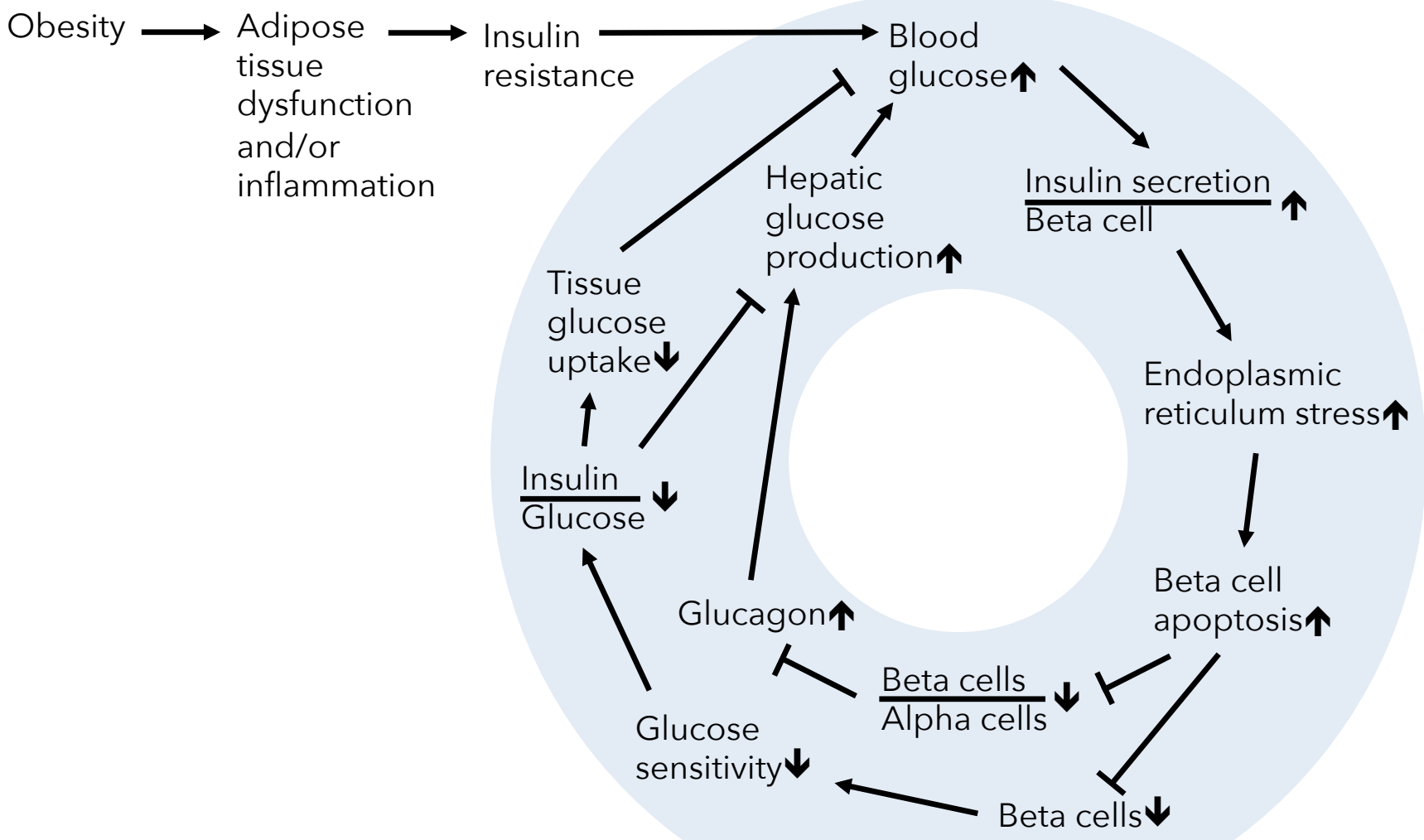

Figure 3. The vicious cycles of type 1 diabetes (A) and type 2 diabetes (B). Short vertical arrows indicate increase $(\boldsymbol{\uparrow})$ or decrease $(\boldsymbol{\Downarrow})$ in parameters that are likely to change exponentially or logistically with age. MHC - major histocompatibility complex, FasL - Fas ligand. 
To break this cycle, blood glucose needs to be lowered for the period of time sufficient for the pancreas to recover proper beta cell numbers. This can be achieved by the supplementation of exogenous insulin, by decreasing insulin resistance, by inhibiting glucagon secretion and hepatic glucose production, or by diminishing glucose reabsorption in kidneys. Increasing insulin sensitivity will also help to prevent the reinitiation of the cycle.

\section{The vicious cycle of Alzheimer's disease}

Alzheimer's disease is the most common neurodegenerative disorder in the elderly. The progressive deterioration of memory, reasoning and language skills leads to confusion, anxiety, frustration and abnormal behavior. Finally, death from aspiration pneumonia may occur. Alzheimer's disease is classically characterized by the build up of amyloid plaques in the brain, along with the appearance of neurofibrillary tangles, synaptic degeneration and neuronal death ${ }^{162,163}$. Amyloid plaques consist of amyloid fibrils, which in turn are composed of amyloid beta $(A \beta)^{164,165}$. $A \beta$ is a peptide of unknown function, cleaved from amyloid precursor protein (APP) by the sequential action of $\beta$ and $Y$-secretases ${ }^{166}$.

The elongated form of $A \beta(A \beta 42)$ can be released as the result of incomplete processing, which is dramatically increased by mutations in APP or presenilins, the key subunits of $Y$-secretase ${ }^{167-169}$. If these mutations are inherited, the familial autosomal dominant early-onset Alzheimer's disease appears, comprising around 5\% of total Alzheimer's cases, with the rest $95 \%$ called late-onset (sporadic) Alzheimer's. Moreover, all known mutations in early-onset familial Alzheimer's map to APP or presenilins, and almost all of them lead to the increased production of $A \beta 42^{167-169}$.

$A \beta 42$ has a particular conformation that is prone to oligomerization and subsequent fibril formation $^{1 / \mathrm{U}-1 / 3}$. The few mutations that do not lead to increased $A \beta 42$ formation nevertheless appear to promote $A \beta$ oligomerization by other means ${ }^{169,174,175}$. Recent studies suggest that $A \beta$ oligomers/protofibrils, rather than mature fibrils, are the primary neurotoxic species ${ }^{171,176-179}$. The most remarkable feature of amyloid is that its molecules in an altered conformation can induce a similarly altered conformation in normal amyloid molecules, as in prion diseases ${ }^{180-184}$. This amyloid property allows the chain reactions of amyloid oligomerization to occur.

I propose the following sequence of events that leads to the formation of toxic $A \beta$ oligomers in sporadic Alzheimer's disease:

(1) In the area of adult neurogenesis, such as the hippocampus ${ }^{185-193}$, a mutation in APP or presenilin spontaneously arises in one cell, leading to the increased production of $A \beta 42^{167,168}$ (mutations are unlikely to occur in postmitotic cells, such as differentiated neurons, as they normally emerge during DNA replication)

(2) Aß42 molecules have an altered conformation that induces their oligomerization (primary nucleation/seed formation) when their local concentration is high enough, such as that created by the somatic mutation of APP or presenilin ${ }^{170-}$ $173,194,195$

(3) A 442 monomers, which are released at low rates by cells without mutations in APP and presenilin, as well as $A \beta 40$ monomers released at high rates, attach to the ends of growing $A \beta$ protofibril chains ${ }^{171,172,196}$

(4) Crucially, $A \beta$ protofibrils also serve as secondary nucleation sites, catalyzing the formation of new oligomers, both from $A \beta 42$ and $A \beta 40^{173,194,195}$

Steps 3 and 4 are continuously repeated, constituting the chain reaction and resulting in the progressive spread of $A \beta$ pathology ${ }^{195}$ (Figure 4A). Recent studies also show that $A \beta$ oligomers can be taken up by cells and can 
spread from synapse to synapse along the defined neurological pathways, such as from the hippocampus to cortical areas ${ }^{182,183}$. A $\beta$ oligomers can exert their toxicity directly ${ }^{171,176-}$ 179,197-199 or via other molecules, such as tau ${ }^{200-}$ 202 , the major component of neurofibrillary tangles, recently also shown to exist in the oligomeric form ${ }^{203}$. A $\beta$ aggregates can also induce the activation of microglia via the scavenger receptor CD36 204,205. Importantly, the deposition of $A \beta$ with age has been shown to follow sigmoidal curve ${ }^{206}$, in line with the in vitro kinetic models of $A \beta$ aggregation $^{171,173,194,195}$ and the logistic growth of Alzheimer's disease mortality (Figure 1).

Considering the hypothetical mechanism proposed here, the only effective way to prevent Alzheimer's disease progression would be to interfere with the chain reaction of $A \beta$ oligomerization. Chemical substances that bind to the oligomer/protofibril ends and block the addition of intact $A \beta$ molecules ${ }^{207-}$ 209, as well as substances that interfere with secondary nucleation ${ }^{210}$, appear to be the best candidates.

\section{The vicious cycles of Parkinson's disease}

Parkinson's disease is the second most common neurodegenerative disorder of old age. Its major symptom is the progressive loss of motor control, manifesting in resting tremor, muscle rigidity, and bradykinesia (slowness), as well as balance, posture and walking problems. Cognitive deficiencies may develop at the late stages of the disease, resulting in 'Parkinson's disease dementia'. If they develop earlier than motor deficits, the disorder is called 'dementia with Lewy bodies'.

The pathology of Parkinson's disease is characterized by the progressive loss of dopaminergic neurons in the substantia nigra pars compacta, which project to the striatum $^{211}$. It is widely agreed that the loss of dopaminergic stimulation of the striatum is the direct cause of motor control deficits ${ }^{212}$. The remaining neurons in the substantia nigra show characteristic inclusions called Lewy bodies and Lewy neurites, which are composed primarily of alpha-synuclein (aS) and ubiquitin ${ }^{213-218}$. When cognitive deficiencies are present alongside impairments in motor control, Lewy bodies and neurites are found in many other brain areas besides the substantia nigra ${ }^{219}$.

Mutations in aS are the only known mutations necessary and sufficient for the development of familial autosomal dominant early-onset Parkinson's disease ${ }^{220-222}$, implying the gain of toxic function by aS. Interestingly, the duplications and triplications of aS gene cause the same disease as missense mutations in aS, with the rate of progression proportional to the gene dosage ${ }^{223-226}$, indicating the toxicity of wild-type aS in elevated concentrations. Additionally, mutations in three other proteins - parkin ${ }^{227}$, PINK-1 ${ }^{228}$ and DJ-1 ${ }^{229}$ - are known to cause autosomal recessive early-onset Parkinson's, suggesting the loss of protective function by these proteins. Altogether, early-onset forms constitute only $5-10 \%$ of all Parkinson's cases but likely highlight the key players in the sporadic disease. Indeed, polymorphisms in the aS gene and promoter are the most significant SNPs associated with sporadic Parkinson's disease $230-237$.

The mechanism of Parkinson's disease initiation and progression might be analogous to that of Alzheimer's disease:

(1) A heterozygous mutation in $\mathrm{aS}^{220-222}$ or the multiplication of the aS gene $e^{223-225}$ arises in a neural progenitor in the subventricular zone $^{238}$, which then travels to the striatum ${ }^{239}$ (as explained above, mutations are very unlikely to occur in postmitotic cells, such as differentiated neurons, as they normally emerge during DNA replication; the subventricular zone and the striatum are directly connected to the substantia nigra via dopaminergic afferents ${ }^{240-242}$; finally, the spontaneous somatic mutation explains the 


\section{A}

Hippocampal adult neurogenesis $\downarrow$

Neural progenitor proliferation

$\downarrow$ APP/presenilin mutation $\stackrel{\downarrow}{\downarrow}$ APP cleavage by presenilin High rate A $\beta 42$ production

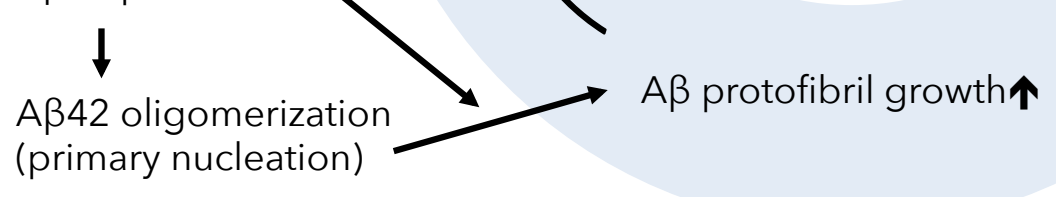

New A $\beta$ oligomers $\uparrow$ (secondary nucleation)

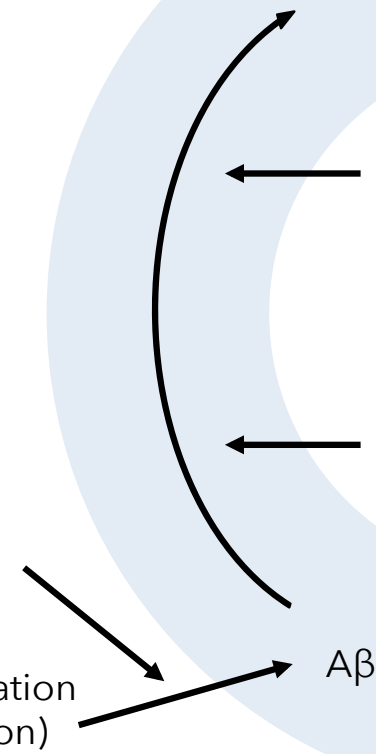

High rate A $\beta 40$ production

$$
\uparrow
$$

Normal neurons

Low rate A 342 production

B Subventricular zone adult neurogenesis $\downarrow$
Neural progenitor
proliferation
$\downarrow$
Spontaneous aS
mutation or
gene multiplication
$\downarrow$
Primary nucleation

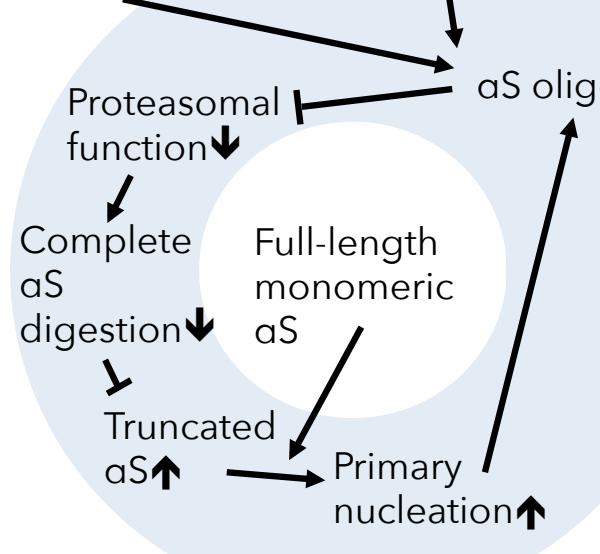

aS protofibril fragmentation $\uparrow$

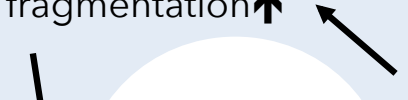

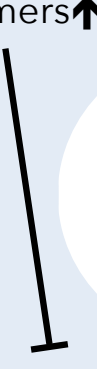

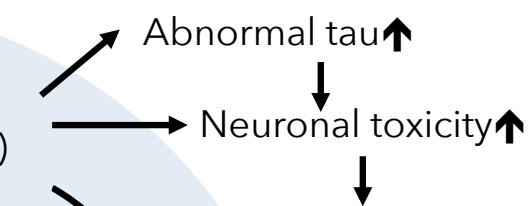

Neurodegeneration $\uparrow$ Cognitive impairment $\uparrow$

Microglia activation $\uparrow$

Amyloid plaques<smiles>[3H]</smiles>

Mature $A \beta$ fibrils

Lewy bodies Lewy neurites

$\uparrow$ Ubiquitin Mature aS fibrils Monomeric $\quad$ protofibril aS growth

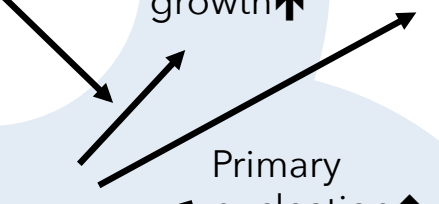

Neuronal toxicity $\uparrow$ Substantia nigra
dopaminergic neurons $\downarrow$
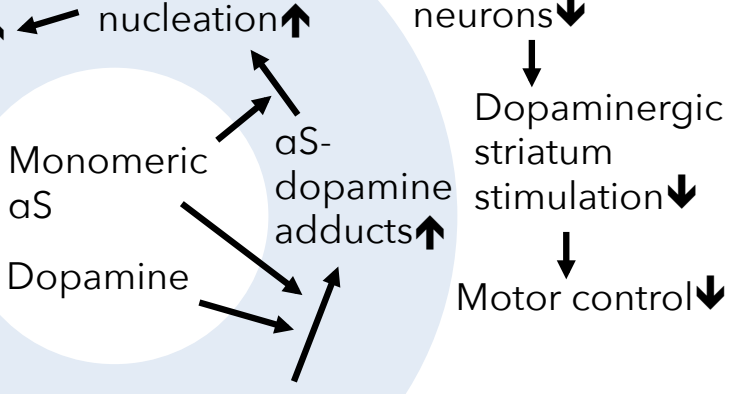
striatum stimulation $\downarrow$ $\downarrow$ Motor control $\downarrow$

Figure 4. The vicious cycles of Alzheimer's disease (A) and Parkinson's disease (B). Short vertical arrows indicate increase $(\boldsymbol{\uparrow})$ or decrease $(\boldsymbol{\Downarrow})$ in parameters that are likely to change exponentially or logistically with age. APP - amyloid precursor protein, A $\beta$ - amyloid beta, A $\beta 42$ 42 amino acids long $A \beta, A \beta 40$ - 40 amino acids long $A \beta, a S$ - alpha synuclein, ROS - reactive oxygen species. 
asymmetric disease manifestation and the random "selection" between the right and the left hemisphere 243,244 , underscored by the symmetric manifestation when the mutation is inherited and hence present in all cells ${ }^{245,246}$ )

(2) A mutation in $\mathrm{aS}^{247-252}$, or the locally increased concentration of $\mathrm{aS}^{253}$ due to the multiplication of the aS gene 254,255 , promotes aS oligomerization (primary nucleation/seed formation)

(3) Oligomers grow into protofibrils by the attachment of monomeric wild type as ${ }^{252}$

(4) Growing protofibrils may fragment to oligomers (secondary nucleation/seed formation $)^{252}$

Steps 3 and 4 are continuously repeated, constituting the chain reaction and resulting in the progressive spread of aS pathology ${ }^{182,183}$ (Figure 4B). Similarly to Alzheimer's disease, substances that bind to aS oligomers/protofibrils and block the addition of monomers appear to be the perfect drug candidates for the treatment of Parkinson's disease ${ }^{256}$.

An additional positive feedback loop may exist $^{257}$ (Figure 4B):

(1) As oligomers spread, they interfere with proteasomal functions ${ }^{258,259}$, leading to the formation of incompletely digested (truncated) as $\mathrm{S}^{257,260}$

(2) Truncated aS is aggregationprone 261,262 and promotes the aggregation of full-length monomeric aS into oligomers and fibrils $257,260,263,264$

Elucidating the exact mechanism of proteasome malfunction and aS truncation may help to design drugs that halt this vicious cycle. However, more promising approaches appear to be the inhibition of the attachment of full-length aS to the truncated one or the inhibition of protofibril elongation ${ }^{265}$.

Accumulating oligomers are toxic to neurons ${ }^{266-268}$. On the contrary, mature fibrils in Lewy bodies and neurites may be neuroprotective by sequestering toxic oligomers $^{217}$. However, the elegant justification of Lewy body-associated toxicity has been proposed based on the stable percentage of Lewy body-bearing neurons ${ }^{269}$. Indeed, Lewy bodies can represent the failure of the ubiquitin-proteasome system ${ }^{217,259,270}$ e.g. due to aS "poisoning" 258,259.

The third vicious cycle involving mitochondria may be present (Figure 4B):

(1) Spreading aS oligomers inhibit mitochondrial Complex $\left.\right|^{271,272}$

(2) The inhibition of Complex I leads to an increase in $\operatorname{ROS}^{273}$

(3) ROS modify aS and dopamine, promoting aS-dopamine covalent binding ${ }^{274-}$ 277

(4) Dopamine adducts promote the conversion of aS into toxic oligomers/protofibrils but prevent the formation of mature fibrils ${ }^{274-277}$

This mitochondrial cycle is supported by the involvement of parkin ${ }^{278}$, PINK-1 ${ }^{279}$ and DJ-1 ${ }^{280-282}$ in mitochondrial maintenance and antioxidant activity, by deficient Complex I activity in Parkinson's disease patients $271,283,284$, as well as by the induction of parkinsonism by mitochondrial Complex I inhibitors and ROS inducers ${ }^{285-289}$. Crucially, toxin-induced parkinsonism is progressive 290,291 and mediated by $\mathrm{aS}^{292}$. In fact, intriguing evidence indicates that an exposure to mitochondrial toxins via the gastrointestinal tract can lead to the accumulation of aS in the enteric nervous system and spreading of the pathology along the nerve fibers to the substantia nigra $293,294$. Mitochondria-targeted antioxidants ${ }^{295}$ and substances that prevent the binding of oligomers to Complex I may help to slow down this vicious cycle. Surprisingly, the clinical trial of MitoO showed no benefit for Parkinson's disease progression ${ }^{296}$, which may indicate that the mitochondrial cycle is not the major one in the sporadic patients. 


\section{Evolutionary perspective}

Why do diseases exist? Why has the perfect body design not evolved in 3 billion years? The answer is that the perfect design cannot exist even in theory. A species design is the result of the preceding evolutionary adaptation to the environment, so the perfect design would mean the perfect adaptation. But the environment is continuously changing, so the design of all species that inhabit it must change as well, to remain adaptive. As there is no possibility for a species to "predict" how the environment will change, the processes of genetic shuffling (sexual reproduction, meiosis, homologous recombination) emerged to constantly vary the design, "in hope" that at least some of the variants will be adapted sufficiently well to the new environment, and thus survive and procreate. In less anthropomorphic terms, species that acquired genetic shuffling adapted faster to the ever-changing environment and outcompeted other species.

\section{A design that is created by random assembling from pieces (of genetic information) is bound to be imperfect. In} case of severe misfortune, a design fails during natal development. More fit individuals may die in childhood or puberty. Those who have managed to live to a ripe-old age may be considered almost perfect (for the time). Similar logic explains interspecies variability in the lifespan. A species whose genetic pool allows better adaptation of the individuals to the current environmental niche that they occupy will have a longer average individual lifespan, relative to a species not fitting its current environment so well (but which may nevertheless survive by boosting the production of new individuals).

Thus, there is no surprise that something in our bodies goes wrong as we grow and age. The question is why do some systems of the body fail more often than others? We can postulate that most failures occur in those systems that deal with the most rapidly changing environmental factors, as the evolution of the species struggles to keep up with them. One group of such factors appears to be the rapidly evolving viruses, bacteria and parasites ${ }^{297,298}$. Hence, many failures are expected in the immune system, resulting both in the inability to counteract pathogens (lethal infections) and in the attack on the self (autoimmune disorders). Indeed, the immune system is central to the development of atherosclerosis, type 1 diabetes and insulin resistance (Figure 5, see also the inflammaging theory ${ }^{299}$ ).

Another rapidly evolving factor is the human civilization itself. Thus, many diseases are expected to be due to modern lifestyles and technogenic environments - overeating, the lack of physical activity, the lack of sleep, close work (books, computers, smartphones), smoking, alcohol consumption, polluted air, processed foods, artificial lighting, noise pollution, electromagnetic pollution, information overload, etc. Insulin resistance is thought to be caused by obesity, which results from overeating, the lack of physical activity and possibly the consumption of processed foods (Figure 5, see also Ref ${ }^{300}$ ).

Some factors do not change with time but are nevertheless impossible to be fully adapted to. Somatic mutations in DNA are one such factor, and lead to cancer ${ }^{1}$. Alzheimer's and Parkinson's diseases also seem to be initiated by spontaneous mutations in $A \beta$ and aS (Figure 5, see also the DNA damage theory of aging ${ }^{301}$ ). ROS are another example of the factor difficult to adapt to. Although aerobic organisms have developed protective systems against these harmful but inevitable byproducts of respiration, and even harnessed them for various antimicrobial and signaling purposes, they are still playing with fire. This is illustrated by the crucial role of ROS in the pathogenesis of atherosclerosis and endothelial dysfunction (Figure 5, see also the free-radical theory of aging $^{302}$ ). 


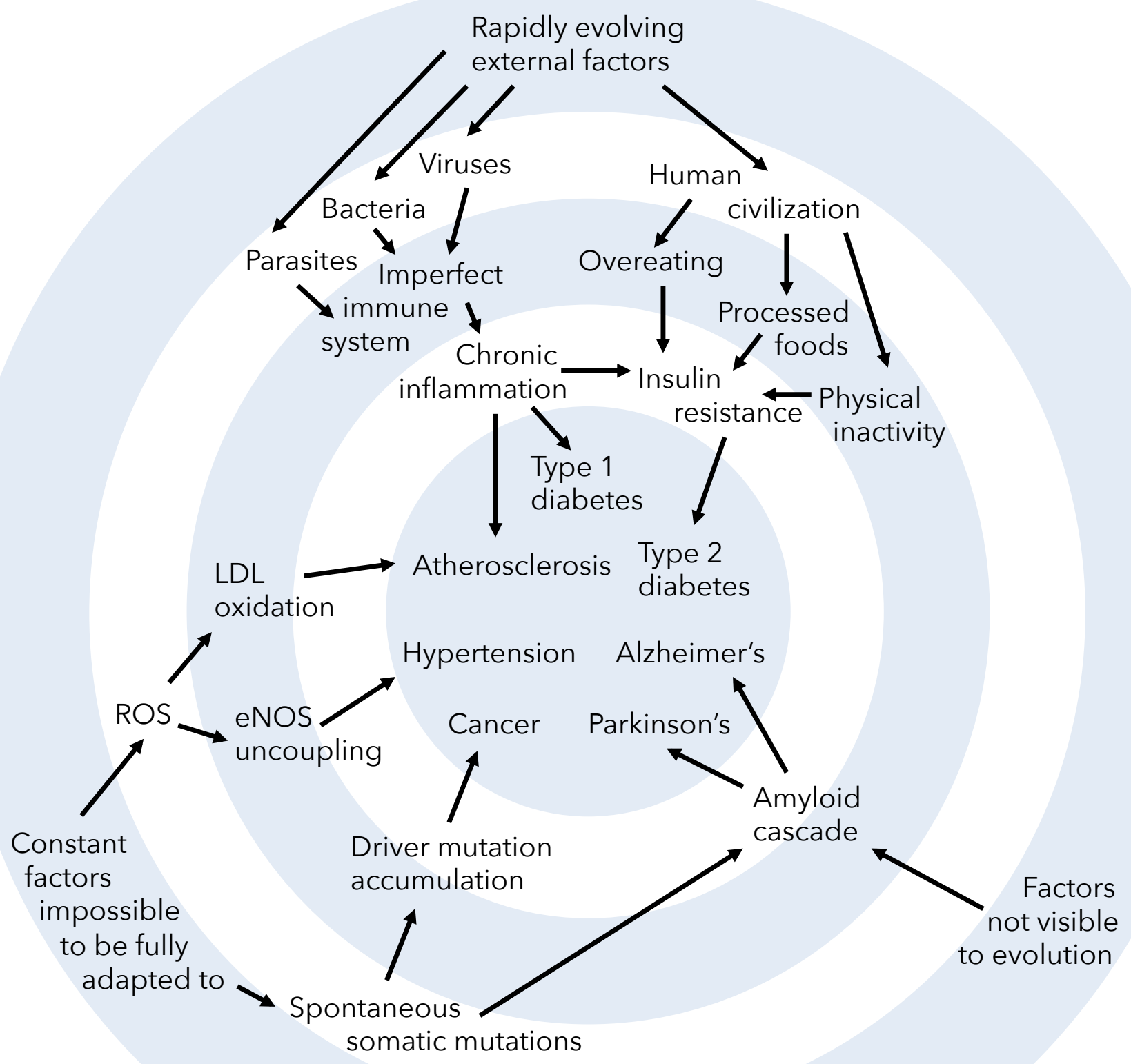

Figure 5. Factors that trigger age-related diseases. ROS - reactive oxygen species, LDL - low density lipoprotein, eNOS - endothelial nitric oxide synthase.

Other dangerous toys are amyloid proteins, such as $A \beta$ and $a S$, that upon a single mutation, truncation or modification, or even simply in increased concentration, can form self-amplifying toxic oligomers. It would probably be possible for the evolution to make these proteins benign, lacking the ability to aggregate, grow and multiply.
Unfortunately, the side effects of amyloid accumulation were not visible to the evolution until the $20^{\text {th }}$ century, when a dramatic increase in life expectancy has occurred ${ }^{303}$. For hunter-gatherers, the life expectancy at age 5 was additional 25 to 50 years ${ }^{304}$, which means that an average human being who survived through infancy and early childhood died at age 30 to 55 for most of our species 
history. Interestingly, 95\% of Alzheimer's disease patients have the sporadic late-onset form, which by definition appears after age $65^{305}$. The cutoff for late-onset Parkinson's disease (90-95\% of patients) varies from age 40 to age 65 according to investigator preferences, and usually is set at age $50^{306}$. Apparently, there was no sufficient selective pressure on our species to develop countermeasures against these diseases (Figure 5).

The factors described above are difficult for evolving species to adapt to. In fact, diseases may represent failed adaptive responses. Moreover, a successful response that is protective during the evolutionarily visible lifespan may turn out to be harmful at older ages. In fact, atherosclerosis can be viewed as the sanitary response of macrophages to atypical substances in the arterial wall, which fails due to the ROS spillover. Arterial stiffening may represent the preventive response of vascular smooth muscle cells to the threat of arterial rupture due to increased stretching, which works but results in increased pulse pressure, leading to other cardiovascular events during the evolutionarily irrelevant part of lifespan. Type 1 diabetes is presumably the immune response to a viral infection that goes wrong because of molecular mimicry or simply due to the fact that immune response is a "delicate war" and any loss of balance may lead to dire consequences. Type 2 diabetes results from the attempt of beta cells to compensate for lifestyle-imposed insulin resistance by maximizing their insulin production, which works for some time but finally leads to the endoplasmic reticulum stress and massive beta-cell death. Insulin resistance itself could be the protective physiological response to obesity (see also the antagonistic pleiotropy theory of aging ${ }^{307}$ ).

The final question is why ARDs are based on positive feedback loops? Positive feedback loops may play the central role in diseases simply because they represent processes with the dynamics that is very difficult for the body to handle. Unlike processes with the linear dynamics, which have a predictable pace and thus are easy to counteract, processes involved in positive feedback loops have the exponential dynamics, which is deceptively slow for most of the timespan but then accelerates very rapidly and unexpectedly. Thus, the body can efficiently neutralize damage arising at a constant rate but cannot cope with damage that appears at an ever-increasing rate. This is likely because during the evolutionarily relevant 55 year lifespan ${ }^{304}$ the body is exposed only to the slow part of the exponent (Figure 1), thus the evolution does not "see" the hazard and the "need" to develop the negative feedback loops to keep the system in check. In other words, the harmful effects of these vicious cycles were not visible to the evolution as they occur after the historical average age of death for our species, and thus no countermeasures have evolved.

\section{Future avenues}

Although much effort has been spent to identify the most likely vicious cycles underlying each ARD, it was necessarily based on the limited and often controversial studies available to date. It is thus quite possible and even expected that when our knowledge expands and deepens, the cycles proposed here would be modified, or even replaced by the newly discovered cycles. To aid those future efforts, I would like to suggest a simple rule. Factors triggering the cycle in question should be distinguished from factors directly participating in that cycle. The former will likely show an association with the disease in epidemiological studies but do not have to change with age. The latter will also show an epidemiological association but in addition must change with age, preferably exponentially or logistically. The examples of triggering factors are LDL and angiotensin ॥ 
concentrations in the blood, type 1 diabetesassociated viruses and obesity. The examples of cycle-participating factors are the amount of oxLDL in the plaques and $A \beta$ oligomers in the brain, the level of $\mathrm{O}_{2}{ }^{--}$in the endothelium and glucose in the blood, pulse pressure, and the number of activated $T$ cells in the pancreas.

This study showed that vicious cycles underlying ARDs are quite diverse and unique, casting serious doubts on the possibility of discovering the single molecular cause of aging and developing the single antiaging pill. Rather, each disease appears to require an individual approach. The theory of vicious cycles helps to identify the most promising targets for the treatment of each ARD. In the end, aging is relevant mostly as an umbrella term for ARDs, as nobody apparently dies of "healthy aging"308.

\section{Methods}

Data acquisition

'Underlying Cause of Death, 1999-2015' data were downloaded via Centers for Disease Control and Prevention Wide-ranging OnLine Data for Epidemiologic Research (CDC WONDER) online database: http://wonder.cdc.gov/controller/datarequest/D76.

The Underlying Cause of Death data are produced by the Mortality Statistics Branch, Division of Vital Statistics, National Center for Health Statistics (NCHS) at the Centers for Disease Control and Prevention (CDC), United States Department of Health and Human Services (US DHHS). Data are based on death certificates for U.S. residents. Each death certificate identifies a single underlying cause of death and demographic data. Mortality information is collected by state registries and provided to the National Vital Statistics System. The population estimates are U.S. Census Bureau estimates of the July 1 resident populations, based on the year 2000 and the year 2010 April 1 census counts. Crude Rates are expressed as the number of deaths reported each calendar year per 100,000 population. Rates and Populations are reported as "Not Applicable" for any subset of ages 85 and over, because population estimates are not available for those ages. The full dataset description is available here:

http://wonder.cdc.gov/wonder/help/ucd.html\#.

Results were grouped by Age Groups, Single-Year Ages were selected in demographics tab, and 2000 to 2015 years were selected in the next tab. 1999 was not included due to population estimates based on a separate 1990 census. All other parameters were left at default settings. Then the data were downloaded separately for each disease, upon its selection in the ICD-10 Codes tab: Insulin-dependent diabetes mellitus (E10), Non-insulin-dependent diabetes mellitus (E11), Parkinson's disease (G20), Alzheimer's disease (G30), Essential (primary) hypertension (I10) and Atherosclerosis (170).

\section{Data analysis}

For analysis, the crude mortality rates were imported into GraphPad Prism 5. Data were analyzed with Nonlinear regression. Userdefined equations were created for the exponential and logistic functions:

$$
\begin{aligned}
& Y=A^{*} \exp \left(b^{\star} x\right) \\
& Y=A /\left(1+\exp \left(-b^{\star}(x-t)\right)\right)
\end{aligned}
$$

The sum of 2 logistic functions was modeled as follows:

$$
\begin{aligned}
& Y 1=A 1 /\left(1+\exp \left(-b 1^{*}(x-t 1)\right)\right) \\
& Y 2=A 2 /(1+\exp (-b 2 *(x-t 2))) \\
& Y=Y 1+Y 2
\end{aligned}
$$

The parameter $A$ was constrained to "Must be between zero and 100000.0" and the parameters $b$ and $t$ to "Must be greater than 0.0". "Initial values, to be fit" for the parameters $A$ and $t$ were set to 1.0 and for the parameter $b$ to 0.5 . All other settings were left by default, e.g. Least squares fit and No weighting.

The hazard functions of the gamma, logistic, normal and Weibull distributions were also tested, but provided inferior fits 
compared to the logistic function or did not converge at all. The hazard functions of the Gumbel and Gompertz distributions are equivalent to the exponential function. The hazard function of the Weibull distribution is equivalent to the power function. Both functions have no upper limit. The sum of two exponential functions did not provide a dramatic improvement in fit over the single exponential function.

\section{References}

1 Belikov, A. V. Fitting the Erlang distribution to cancer incidence by age may predict key carcinogenic events. bioRxiv (2016).

2 Nordling, C. O. A new theory on cancer-inducing mechanism. British journal of cancer 7, 68-72 (1953).

3 Knudson, A. G. Two genetic hits (more or less) to cancer. Nature reviews. Cancer 1, 157-162, doi:10.1038/35101031 (2001).

4 Armitage, P. \& Doll, R. The age distribution of cancer and a multi-stage theory of carcinogenesis. British journal of cancer 91, 1983-1989, doi:10.1038/sj.bjc.6602297 (2004).

5 Pon, J. R. \& Marra, M. A. Driver and passenger mutations in cancer. Annual review of pathology 10, 25-50, doi:10.1146/annurev-pathol-012414040312 (2015).

6 Celeng, C., Takx, R. A., Ferencik, M. \& Maurovich-Horvat, P. Non-invasive and invasive imaging of vulnerable coronary plaque. Trends Cardiovasc Med 26, 538-547,

doi:10.1016/j.tcm.2016.03.005 (2016).

7 Stary, H. C. The sequence of cell and matrix changes in atherosclerotic lesions of coronary arteries in the first forty years of life. European heart journal 11 Suppl E, 3-19(1990).
8 Napoli, C. et al. Fatty streak formation occurs in human fetal aortas and is greatly enhanced by maternal hypercholesterolemia. Intimal accumulation of low density lipoprotein and its oxidation precede monocyte recruitment into early atherosclerotic lesions. J Clin Invest 100, 2680-2690, doi:10.1172/JCl119813 (1997).

9 McGill, H. C., Jr. et al. Origin of atherosclerosis in childhood and adolescence. The American journal of clinical nutrition 72, 1307S-1315S (2000).

10 Ota, H. et al. Hemorrhage and large lipid-rich necrotic cores are independently associated with thin or ruptured fibrous caps: an in vivo 3T MRI study. Arterioscler Thromb Vasc Biol 29, 1696-1701,

doi:10.1161/ATVBAHA.109.192179 (2009).

11 Chamie, D., Wang, Z., Bezerra, H., Rollins, A. M. \& Costa, M. A. Optical Coherence Tomography and Fibrous Cap Characterization. Current cardiovascular imaging reports 4, 276283, doi:10.1007/s12410-011-9090-8 (2011).

12 Hulsmans, M. \& Holvoet, P. The vicious circle between oxidative stress and inflammation in atherosclerosis. J Cell Mol Med 14, 70-78, doi:10.1111/j.15824934.2009.00978.x(2010).

13 Deng, $X$. et al. Luminal surface concentration of lipoprotein (LDL) and its effect on the wall uptake of cholesterol by canine carotid arteries. Journal of Vascular Surgery 21, 135145, doi:10.1016/S07415214(95)70252-0 (1995).

14 Kaufman, H. W., Blatt, A. J., Huang, X., Odeh, M. A. \& Superko, H. R. Blood cholesterol trends 2001-2011 in the United States: analysis of 105 million patient records. PLoS One 8, e63416, 
doi:10.1371/journal.pone.0063416 (2013).

15 Lassègue, B. \& Griendling, K. K. NADPH Oxidases: Functions and Pathologies in the Vasculature. Arteriosclerosis, Thrombosis, and Vascular Biology 30, 653-661, doi:10.1161/ATVBAHA.108.181610 (2010).

16 Drummond, G. R. \& Sobey, C. G. Endothelial NADPH oxidases: which NOX to target in vascular disease? Trends in Endocrinology \& Metabolism 25, 452-463, doi:10.1016/j.tem.2014.06.012 (2014).

17 Steinberg, D. \& Witztum, J. L. Oxidized Low-Density Lipoprotein and Atherosclerosis. Arteriosclerosis, Thrombosis, and Vascular Biology 30, 2311-2316,

doi:10.1161/ATVBAHA.108.179697 (2010).

18 Khan, B. V., Parthasarathy, S. S., Alexander, R. W. \& Medford, R. M. Modified low density lipoprotein and its constituents augment cytokineactivated vascular cell adhesion molecule-1 gene expression in human vascular endothelial cells. J Clin Invest 95, 1262-1270, doi:10.1172/JCl117776 (1995).

19 Takei, A., Huang, Y. \& Lopes-Virella, M. F. Expression of adhesion molecules by human endothelial cells exposed to oxidized low density lipoprotein. Influences of degree of oxidation and location of oxidized LDL. Atherosclerosis 154, 79-86 (2001).

20 Keiper, T. et al. The role of junctional adhesion molecule-C (JAM-C) in oxidized LDL-mediated leukocyte recruitment. FASEB journal : official publication of the Federation of American Societies for Experimental Biology 19, 2078-2080, doi:10.1096/fj.05-4196fje (2005).
21 Gleissner, C. A., Leitinger, N. \& Ley, K. Effects of Native and Modified LowDensity Lipoproteins on Monocyte Recruitment in Atherosclerosis. Hypertension 50, 276-283, doi:10.1161/HYPERTENSIONAHA.107. 089854 (2007).

22 Fang, F. et al. Myocardin-related transcription factor A mediates OxLDLinduced endothelial injury. Circulation research 108, 797-807, doi:10.1161/CIRCRESAHA.111.240655 (2011).

23 Febbraio, M. et al. Targeted disruption of the class B scavenger receptor CD36 protects against atherosclerotic lesion development in mice. J Clin Invest 105, 1049-1056 doi:10.1172/JCl9259 (2000).

24 Collot-Teixeira, S., Martin, J., McDermott-Roe, C., Poston, R. \& McGregor, J. L. CD36 and macrophages in atherosclerosis. Cardiovascular Research 75, 468-477 (2007).

25 Schrijvers, D. M., De Meyer, G. R. Y., Herman, A. G. \& Martinet, W. Phagocytosis in atherosclerosis: Molecular mechanisms and implications for plaque progression and stability. Cardiovascular Research 73, 470-480 (2007).

26 Park, Y. M. CD36, a scavenger receptor implicated in atherosclerosis. Exp Mol Med 46, e99, doi:10.1038/emm.2014.38 (2014).

27 Judkins, C. P. et al. Direct evidence of a role for Nox2 in superoxide production, reduced nitric oxide bioavailability, and early atherosclerotic plaque formation in ApoE-/- mice. American journal of physiology. Heart and circulatory physiology 298, H24-32, doi:10.1152/ajpheart.00799.2009 (2010). 
28 Dupre-Crochet, S., Erard, M. \& Nubetae, O. ROS production in phagocytes: why, when, and where? Journal of leukocyte biology 94, 657670, doi:10.1189/jlb.1012544 (2013).

29 Peluso, I., Morabito, G., Urban, L., loannone, F. \& Serafini, M. Oxidative stress in atherosclerosis development: the central role of LDL and oxidative burst. Endocrine, metabolic \& immune disorders drug targets 12, 351-360 (2012).

30 Ait-Oufella, H., Taleb, S., Mallat, Z. \& Tedgui, A. Recent advances on the role of cytokines in atherosclerosis. Arterioscler Thromb Vasc Biol 31, 969979, doi:10.1161/ATVBAHA.110.207415 (2011).

31 Ramji, D. P. \& Davies, T. S. Cytokines in atherosclerosis: Key players in all stages of disease and promising therapeutic targets. Cytokine \& growth factor reviews 26, 673-685, doi:10.1016/j.cytogfr.2015.04.003 (2015).

32 Chistiakov, D. A., Bobryshev, Y. V. \& Orekhov, A. N. Macrophage-mediated cholesterol handling in atherosclerosis. Journal of Cellular and Molecular Medicine 20, 17-28, doi:10.1111/jcmm.12689 (2016).

33 Tabas, I. Macrophage death and defective inflammation resolution in atherosclerosis. Nature reviews. Immunology $\quad 10, \quad 36-46$, doi:10.1038/nri2675 (2010).

34 Dollery, C. M. \& Libby, P. Atherosclerosis and proteinase activation. Cardiovasc Res 69, 625-635, doi:10.1016/j.cardiores.2005.11.003 (2006).

35 Newby, A. C. Metalloproteinase expression in monocytes and macrophages and its relationship to atherosclerotic plaque instability.
Arterioscler Thromb Vasc Biol 28, 2108-

2114,

doi:10.1161/ATVBAHA.108.173898 (2008).

36 Wickline, S. A., Neubauer, A. M., Winter, P., Caruthers, S. \& Lanza, G. Applications of nanotechnology to atherosclerosis, thrombosis, and vascular biology. Arterioscler Thromb Vasc Biol 26, 435-441, doi:10.1161/01.ATV.0000201069.4755 $0.8 b$ (2006).

37 Antoniades, C. et al. Nanoparticles: a promising therapeutic approach in atherosclerosis. Current drug delivery 7, 303-311 (2010).

38 Fredman, G. et al. Targeted nanoparticles containing the proresolving peptide Ac2-26 protect against advanced atherosclerosis in hypercholesterolemic mice. Science translational medicine 7, 275ra220, doi:10.1126/scitranslmed.aaa1065 (2015).

39 Franklin, S. S. et al. Hemodynamic patterns of age-related changes in blood pressure. The Framingham Heart Study. Circulation 96, 308-315 (1997).

40 Mayet, J. \& Hughes, A. Cardiac and vascular pathophysiology in hypertension. Heart 89, 1104-1109 (2003).

41 Tanaka, $H$. et al. Hemodynamic Correlates of Blood Pressure in Older Adults: The Atherosclerosis Risk in Communities (ARIC) Study. Journal of clinical hypertension 18, 1222-1227, doi:10.1111/jch.12898 (2016).

42 Messerli, F. H. et al. Essential hypertension in the elderly: haemodynamics, intravascular volume, plasma renin activity, and circulating catecholamine levels. Lancet 2, 983-986 (1983).

43 Julius, S. Transition from high cardiac output to elevated vascular resistance in 
hypertension. American heart journal 116, 600-606 (1988).

44 Palatini, P. \& Julius, S. The role of cardiac autonomic function in hypertension and cardiovascular disease. Current hypertension reports 11, 199-205 (2009).

45 Atlas, S. A. The renin-angiotensin aldosterone system: pathophysiological role and pharmacologic inhibition. Journal of managed care pharmacy : JMCP 13, 9-20, doi:10.18553/jmcp.2007.13.s8-b.9 (2007).

46 te Riet, L., van Esch, J. H. M., Roks, A. J. M., van den Meiracker, A. H. \& Danser, A. H. J. Hypertension: ReninAngiotensin-Aldosterone System Alterations. Circulation research 116, 960-975,

doi:10.1161/CIRCRESAHA.116.303587 (2015).

47 Noth, R. H., Lassman, M. N., Tan, S. Y., Fernandez-Cruz, A., Jr. \& Mulrow, P. J. Age and the renin-aldosterone system. Archives of internal medicine 137, 1414-1417 (1977).

48 Ogihara, T. et al. Studies on the reninangiotensin-aldosterone system in elderly hypertensive patients with an angiotensin II antagonist. Clinical science 57, 461-463 (1979).

49 Nakamaru, M. et al. Effect of age on active and inactive plasma renin in normal subjects and in patients with essential hypertension. Journal of the American Geriatrics Society 29, 379382 (1981).

50 Guyenet, P. G. The sympathetic control of blood pressure. Nat Rev Neurosci 7, 335-346 (2006).

51 Mancia, G. \& Grassi, G. The autonomic nervous system and hypertension. Circulation research 114, 1804-1814, doi:10.1161/CIRCRESAHA.114.302524 (2014).
52 Philipp, T., Distler, A. \& Cordes, U. Sympathetic nervous system and bloodpressure control in essential hypertension. Lancet 2, 959-963 (1978).

53 Kjeldsen, S. E., Schork, N. J., Leren, P. \& Eide, I. K. Arterial plasma norepinephrine correlates to blood pressure in middle-aged men with sustained essential hypertension. American heart journal 118, 775-781 (1989).

54 Yamada, Y., Miyajima, E., Tochikubo, O., Matsukawa, T. \& Ishii, M. Agerelated changes in muscle sympathetic nerve activity in essential hypertension. Hypertension 13, 870-877 (1989).

55 Dudzinski, D. M., Igarashi, J., Greif, D. \& Michel, T. The regulation and pharmacology of endothelial nitric oxide synthase. Annual review of pharmacology and toxicology 46, 235276,

doi:10.1146/annurev.pharmtox.44.101 802.121844 (2006).

56 Forte, P. et al. Basal nitric oxide synthesis in essential hypertension. Lancet 349, 837-842, doi:10.1016/S0140-6736(96)07631-3 (1997).

57 Node, K., Kitakaze, M., Yoshikawa, H., Kosaka, H. \& Hori, M. Reduced plasma concentrations of nitrogen oxide in individuals with essential hypertension. Hypertension 30, 405-408 (1997).

58 Hermann, M., Flammer, A. \& Luscher, T. F. Nitric oxide in hypertension. Journal of clinical hypertension 8, 17-29 (2006).

59 Landmesser, $U$. et al. Oxidation of tetrahydrobiopterin leads to uncoupling of endothelial cell nitric oxide synthase in hypertension. J Clin Invest 111, 1201-1209, doi:10.1172/JCl14172 (2003).

60 Swartz, S. L., Williams, G. H., Hollenberg, N. K., Dluhy, R. G. \& Moore, $\mathrm{T}$. J. Primacy of the renin-angiotensin 
system in mediating the aldosterone response to sodium restriction. The Journal of clinical endocrinology and metabolism 50, 1071-1074, doi:10.1210/jcem-50-6-1071 (1980).

61 Graudal, N. A., Hubeck-Graudal, T. \& Jurgens, G. Effects of low-sodium diet vs. high-sodium diet on blood pressure, renin, aldosterone, catecholamines, cholesterol, and triglyceride (Cochrane Review). American journal of hypertension 25, 1-15, doi:10.1038/ajh.2011.210 (2012).

62 Higuchi, S. et al. Angiotensin II signal transduction through the AT1 receptor: novel insights into mechanisms and pathophysiology. Clinical science 112, 417-428, doi:10.1042/CS20060342 (2007).

63 Matsuno, K. et al. Nox1 is involved in angiotensin II-mediated hypertension: a study in Nox1-deficient mice. Circulation 112, 2677-2685, doi:10.1161/CIRCULATIONAHA.105.57 3709 (2005).

64 Akasaki, T. et al. Increased expression of gp91 phox homologues of $\mathrm{NAD}(\mathrm{P}) \mathrm{H}$ oxidase in the aortic media during chronic hypertension: involvement of the renin-angiotensin system. Hypertension research : official journal of the Japanese Society of Hypertension 29, 813-820, doi:10.1291/hypres.29.813 (2006).

65 Gavazzi, G. et al. Decreased blood pressure in NOX1-deficient mice. FEBS letters 580, 497-504, doi:10.1016/j.febslet.2005.12.049 (2006).

66 Wang, P. et al. Contribution of different Nox homologues to cardiac remodeling in two-kidney two-clip renovascular hypertensive rats: effect of valsartan. Pharmacological research 55, 408-417, doi:10.1016/j.phrs.2007.01.016 (2007).
67 Liochev, S. I. \& Fridovich, I. The effects of superoxide dismutase on $\mathrm{H} 2 \mathrm{O} 2$ formation. Free radical biology \& medicine 42, 1465-1469, doi:10.1016/j.freeradbiomed.2007.02.0 15 (2007).

68 Cai, H. et al. NAD $(\mathrm{P}) \mathrm{H}$ oxidase-derived hydrogen peroxide mediates endothelial nitric oxide production in response to angiotensin II. The Journal of biological chemistry 277, 48311 48317, doi:10.1074/jbc.M208884200 (2002).

69 Szabo, C., Ischiropoulos, H. \& Radi, R. Peroxynitrite:

biochemistry, pathophysiology and development of therapeutics. Nature reviews. Drug discovery 6, 662-680, doi:10.1038/nrd2222 (2007).

70 Vasquez-Vivar, J., Whitsett, J., Martasek, P., Hogg, N. \& Kalyanaraman, B. Reaction of tetrahydrobiopterin with superoxide: EPR-kinetic analysis and characterization of the pteridine radical. Free radical biology \& medicine 31, 975-985 (2001).

71 Milstien, S. \& Katusic, Z. Oxidation of tetrahydrobiopterin by peroxynitrite: implications for vascular endothelial function. Biochemical and biophysical research communications 263, 681-684, doi:10.1006/bbrc.1999.1422 (1999).

72 Vasquez-Vivar, J. et al. Superoxide generation by endothelial nitric oxide synthase: the influence of cofactors. Proceedings of the National Academy of Sciences of the United States of America 95, 9220-9225 (1998).

73 Vasquez-Vivar, J., Martasek, P., Whitsett, J., Joseph, J. \& Kalyanaraman, B. The ratio between tetrahydrobiopterin and oxidized tetrahydrobiopterin analogues controls superoxide release from endothelial nitric oxide synthase: an EPR spin trapping study. The 
Biochemical journal 362, 733-739 (2002).

74 Feihl, F., Liaudet, L., Levy, B. I. \& Waeber, B. Hypertension and microvascular remodelling. Cardiovasc Res 78, 274-285, doi:10.1093/cvr/cvn022 (2008).

75 Arribas, S. M., Gonzalez, C., Graham, D., Dominiczak, A. F. \& McGrath, J. C. Cellular changes induced by chronic nitric oxide inhibition in intact rat basilar arteries revealed by confocal microscopy. Journal of hypertension 15, 1685-1693 (1997).

76 Mulvany, M. J. Small artery remodelling in hypertension. Basic \& clinical pharmacology \& toxicology $110,49-55$, doi:10.1111/j.1742-7843.2011.00758.x (2012).

77 d'Uscio, L. V., Milstien, S., Richardson, D., Smith, L. \& Katusic, Z. S. Long-term vitamin $C$ treatment increases vascular tetrahydrobiopterin levels and nitric oxide synthase activity. Circulation research 92, 88-95 (2003).

78 McCarty, M. F., Barroso-Aranda, J. \& Contreras, F. High-dose folate and dietary purines promote scavenging of peroxynitrite-derived radicals--clinical potential in inflammatory disorders. Medical hypotheses 73, 824-834, doi:10.1016/j.mehy.2008.09.058 (2009).

79 Crabtree, M. J. \& Channon, K. M. Synthesis and recycling of tetrahydrobiopterin in endothelial function and vascular disease. Nitric oxide : biology and chemistry / official journal of the Nitric Oxide Society 25, 81-88, doi:10.1016/j.niox.2011.04.004 (2011).

80 Cunnington, C. et al. Systemic and vascular oxidation limits the efficacy of oral tetrahydrobiopterin treatment in patients with coronary artery disease. Circulation 125, 1356-1366,
doi:10.1161/CIRCULATIONAHA.111.03 8919 (2012).

81 Whitsett, J. et al. Human endothelial dihydrofolate reductase low activity limits vascular tetrahydrobiopterin recycling. Free radical biology \& medicine 63, 143-150, doi:10.1016/j.freeradbiomed.2013.04.0 35 (2013).

82 Quinn, U., Tomlinson, L. A. \& Cockcroft, J. R. Arterial stiffness. JRSM Cardiovasc Dis 1, doi:10.1258/cvd.2012.012024 (2012).

83 AlGhatrif, $M$. et al. Longitudinal trajectories of arterial stiffness and the role of blood pressure: the Baltimore Longitudinal Study of Aging. Hypertension 62, 934-941, doi:10.1161/HYPERTENSIONAHA.113. 01445 (2013).

84 Liao, D. et al. Arterial stiffness and the development of hypertension. The ARIC study. Hypertension 34, 201-206 (1999).

85 Dernellis, J. \& Panaretou, M. Aortic stiffness is an independent predictor of progression to hypertension in nonhypertensive subjects. Hypertension 45, 426-431, doi:10.1161/01.HYP.0000157818.5887 8.93 (2005).

86 Yambe, M. et al. Arterial stiffness and progression to hypertension in Japanese male subjects with high normal blood pressure. Journal of hypertension 25, 87-93, doi:10.1097/01.hjh.0000254375.73241. e2 (2007).

87 Peralta, C. A. et al. Structural and functional vascular alterations and incident hypertension in normotensive adults: the Multi-Ethnic Study of Atherosclerosis. American journal of epidemiology 171, 63-71, doi:10.1093/aje/kwp319 (2010). 
88 Takase, H. et al. Brachial-ankle pulse wave velocity predicts increase in blood pressure and onset of hypertension. American journal of hypertension 24, 667-673, doi:10.1038/ajh.2011.19 (2011).

89 Najjar, S. S. et al. Pulse wave velocity is an independent predictor of the longitudinal increase in systolic blood pressure and of incident hypertension in the Baltimore Longitudinal Study of Aging. Journal of the American College of Cardiology 51, 1377-1383, doi:10.1016/j.jacc.2007.10.065 (2008).

90 Vlachopoulos, C., Aznaouridis, K. \& Stefanadis, C. Prediction of cardiovascular events and all-cause mortality with arterial stiffness: a systematic review and meta-analysis. Journal of the American College of Cardiology 55, 1318-1327, doi:10.1016/j.jacc.2009.10.061 (2010).

91 McEniery, C. M. et al. An analysis of prospective risk factors for aortic stiffness in men: 20-year follow-up from the Caerphilly prospective study. Hypertension 56, 36-43, doi:10.1161/HYPERTENSIONAHA.110. 150896 (2010).

92 Franklin, S. S. Arterial stiffness and hypertension: a two-way street? Hypertension 45, 349-351, doi:10.1161/01.HYP.0000157819.3161 1.87 (2005).

93 Tomiyama, H. \& Yamashina, A. Arterial stiffness in prehypertension: a possible vicious cycle. Journal of cardiovascular translational research 5, 280-286, doi:10.1007/s12265-011-9345-4 (2012).

94 Humphrey, J. D., Harrison, D. G., Figueroa, C. A., Lacolley, P. \& Laurent, S. Central Artery Stiffness in Hypertension and Aging: A Problem With Cause and Consequence. Circulation research 118, 379-381,
doi:10.1161/CIRCRESAHA.115.307722 (2016).

95 Rattazzi, M., Bertacco, E., Puato, M., Faggin, E. \& Pauletto, P. Hypertension and vascular calcification: a vicious cycle? Journal of hypertension 30, 1885-1893,

doi:10.1097/HJH.0b013e328356c257 (2012).

96 Tsamis, A., Krawiec, J. T. \& Vorp, D. A. Elastin and collagen fibre microstructure of the human aorta in ageing and disease: a review. Journal of the Royal Society, Interface / the Royal Society 10, 20121004, doi:10.1098/rsif.2012.1004 (2013).

97 Lemarie, C. A., Tharaux, P. L. \& Lehoux, S. Extracellular matrix alterations in hypertensive vascular remodeling. Journal of molecular and cellular cardiology 48, 433-439, doi:10.1016/j.yjmcc.2009.09.018 (2010).

98 Liu, W. F. Mechanical regulation of cellular phenotype: implications for vascular tissue regeneration. Cardiovasc Res 95, 215-222, doi:10.1093/cvr/cvs168 (2012).

99 Willcox, A., Richardson, S. J., Bone, A. J., Foulis, A. K. \& Morgan, N. G. Analysis of islet inflammation in human type 1 diabetes. Clinical and experimental immunology 155, 173-181, doi:10.1111/j.1365-2249.2008.03860.x (2009).

100 Lehuen, A., Diana, J., Zaccone, P. \& Cooke, A. Immune cell crosstalk in type 1 diabetes. Nature reviews. Immunology 10, 501-513, doi:10.1038/nri2787 (2010).

101 Boldison, J. \& Wong, F. S. Immune and Pancreatic beta Cell Interactions in Type 1 Diabetes. Trends in endocrinology and metabolism: TEM 27, 856-867, doi:10.1016/j.tem.2016.08.007 (2016). 
102 Prentki, M. \& Nolan, C. J. Islet beta cell failure in type 2 diabetes. J Clin Invest 116, 1802-1812, doi:10.1172/JCl29103 (2006).

103 Defronzo, R. A. Banting Lecture. From the triumvirate to the ominous octet: a new paradigm for the treatment of type 2 diabetes mellitus. Diabetes 58, 773795, doi:10.2337/db09-9028 (2009).

104 Pietropaolo, M., Surhigh, J. M., Nelson, P. W. \& Eisenbarth, G. S. Primer: immunity and autoimmunity. Diabetes 57, 2872-2882, doi:10.2337/db07-1691 (2008).

105 Morel, P. A. Dendritic cell subsets in type 1 diabetes: friend or foe? Frontiers in immunology 4, 415, doi:10.3389/fimmu.2013.00415 (2013).

106 Van Gassen, N. et al. Concise Review: Macrophages: Versatile Gatekeepers During Pancreatic beta-Cell Development, Injury, and Regeneration. Stem cells translational medicine 4, 555-563, doi:10.5966/sctm.2014-0272 (2015).

107 Filippi, C. M. \& von Herrath, M. G. Viral trigger for type 1 diabetes: pros and cons. Diabetes 57, 2863-2871, doi:10.2337/db07-1023 (2008).

108 Goldberg, E. \& Krause, I. Infection and type 1 diabetes mellitus - a two edged sword? Autoimmunity reviews 8, 682686, doi:10.1016/j.autrev.2009.02.017 (2009).

109 Paun, A., Yau, C. \& Danska, J. S. Immune recognition and response to the intestinal microbiome in type 1 diabetes. Journal of autoimmunity 71, 10-18, doi:10.1016/j.jaut.2016.02.004 (2016).

110 Unanue, E. R. Antigen presentation in the autoimmune diabetes of the NOD mouse. Annual review of immunology 32, 579-608, doi:10.1146/annurevimmunol-032712-095941 (2014).
111 Agace, W. W. Tissue-tropic effector T cells: generation and targeting opportunities. Nature reviews. Immunology 6, 682-692, doi:10.1038/nri1869 (2006).

112 Kurts, C., Miller, J. F., Subramaniam, R. M., Carbone, F. R. \& Heath, W. R. Major histocompatibility complex class Irestricted cross-presentation is biased towards high dose antigens and those released during cellular destruction. The Journal of experimental medicine 188, 409-414 (1998).

113 de Jersey, J. et al. Beta cells cannot directly prime diabetogenic CD8 T cells in nonobese diabetic mice. Proceedings of the National Academy of Sciences of the United States of America 104, 1295-1300, doi:10.1073/pnas.0610057104 (2007).

114 Castellino, F. \& Germain, R. N. Cooperation between CD4+ and CD8+ $T$ cells: when, where, and how. Annual review of immunology 24, 519-540, doi:10.1146/annurev.immunol.23.0217 04.115825 (2006).

115 Calderon, B., Carrero, J. A. \& Unanue, E. R. The central role of antigen presentation in islets of Langerhans in autoimmune diabetes. Current opinion in immunology 26, 32-40, doi:10.1016/j.coi.2013.10.011 (2014).

116 Thomas, H. E., Trapani, J. A. \& Kay, T. $W$. The role of perforin and granzymes in diabetes. Cell death and differentiation 17, 577-585, doi:10.1038/cdd.2009.165 (2010).

117 Skowera, A. et al. beta-cell-specific CD8 $T$ cell phenotype in type 1 diabetes reflects chronic autoantigen exposure. Diabetes 64, 916-925, doi:10.2337/db14-0332 (2015).

118 Di Lorenzo, T. P., Peakman, M. \& Roep, B. O. Translational mini-review series on type 1 diabetes: Systematic analysis of $T$ cell epitopes in autoimmune diabetes. 
Clinical and experimental immunology 148, 1-16, doi:10.1111/j.13652249.2006.03244.x (2007).

119 McGinty, J. W., Marre, M. L., Bajzik, V., Piganelli, J. D. \& James, E. A. T cell epitopes and post-translationally modified epitopes in type 1 diabetes. Current diabetes reports 15, 90, doi:10.1007/s11892-015-0657-7 (2015).

120 Vanderlugt, C. L. \& Miller, S. D. Epitope spreading in immune-mediated diseases: implications for immunotherapy. Nature reviews. Immunology 2, 85-95, doi:10.1038/nri724 (2002).

121 von Herrath, M., Sanda, S. \& Herold, K. Type 1 diabetes as a relapsingremitting disease? Nature reviews. Immunology 7, 988-994, doi:10.1038/nri2192 (2007).

122 Amrani, A. et al. Progression of autoimmune diabetes driven by avidity maturation of a T-cell population. Nature 406, 739-742, doi:10.1038/35021081 (2000).

123 Ferrannini, E. et al. Progression to diabetes in relatives of type 1 diabetic patients: mechanisms and mode of onset. Diabetes 59, 679-685, doi:10.2337/db09-1378 (2010).

124 Koskinen, M. K. et al. Reduced beta-cell function in early preclinical type 1 diabetes. European journal of endocrinology / European Federation of Endocrine Societies 174, 251-259, doi:10.1530/EJE-15-0674 (2016).

125 Hess, P. R. et al. Selective deletion of antigen-specific CD8+ $T$ cells by MHC class I tetramers coupled to the type I ribosome-inactivating protein saporin. Blood 109, 3300-3307, doi:10.1182/blood-2006-06-028001 (2007).

126 Wang, W. et al. A biodegradable killer microparticle to selectively deplete antigen-specific $T$ cells in vitro and in vivo. Oncotarget 7, 12176-12190, doi:10.18632/oncotarget.7519 (2016).

127 Casares, S. et al. Down-regulation of diabetogenic CD4+ T cells by a soluble dimeric peptide-MHC class II chimera. Nature immunology 3, 383-391, doi:10.1038/ni770 (2002).

128 Meier, J. J. \& Bonadonna, R. C. Role of reduced beta-cell mass versus impaired beta-cell function in the pathogenesis of type 2 diabetes. Diabetes care 36 Suppl 2, S113-119, doi:10.2337/dcS132008 (2013).

129 Lavau, M., Fried, S. K., Susini, C. \& Freychet, P. Mechanism of insulin resistance in adipocytes of rats fed a high-fat diet. Journal of lipid research 20, 8-16 (1979).

130 Eissing, L. et al. De novo lipogenesis in human fat and liver is linked to ChREBPbeta and metabolic health. Nature communications $4, \quad 1528$, doi:10.1038/ncomms2537 (2013).

131 Strissel, K. J. et al. Adipocyte death, adipose tissue remodeling, and obesity complications. Diabetes 56, 2910-2918, doi:10.2337/db07-0767 (2007).

132 Feuerer, M. et al. Lean, but not obese, fat is enriched for a unique population of regulatory $T$ cells that affect metabolic parameters. Nature medicine 15, 930-939, doi:10.1038/nm.2002 (2009).

133 Yang, $H$. et al. Obesity increases the production of proinflammatory mediators from adipose tissue $T$ cells and compromises TCR repertoire diversity: implications for systemic inflammation and insulin resistance. Journal of immunology 185, 18361845, doi:10.4049/jimmunol.1000021 (2010).

134 Strissel, K. J. et al. T-cell recruitment and Th1 polarization in adipose tissue during diet-induced obesity in C57BL/6 
mice. Obesity 18, 1918-1925, doi:10.1038/oby.2010.1 (2010).

135 Winer, D. A. et al. B cells promote insulin resistance through modulation of $T$ cells and production of pathogenic IgG antibodies. Nature medicine 17, 610-617, doi:10.1038/nm.2353 (2011).

$136 \mathrm{Han}, \mathrm{M}$. S. et al. JNK expression by macrophages promotes obesityinduced insulin resistance and inflammation. Science 339, 218-222, doi:10.1126/science.1227568 (2013).

137 Saad, M. F. et al. Sequential changes in serum insulin concentration during development of non-insulin-dependent diabetes. Lancet 1, 1356-1359 (1989).

138 Levy, J., Atkinson, A. B., Bell, P. M., McCance, D. R. \& Hadden, D. R. Betacell deterioration determines the onset and rate of progression of secondary dietary failure in type 2 diabetes mellitus: the 10-year follow-up of the Belfast Diet Study. Diabetic medicine : a journal of the British Diabetic Association 15, 290-296, doi:10.1002/(SICl)1096-

9136(199804)15:4<290::AID-

DIA570>3.0.CO;2-M (1998).

139 Mason, C. C., Hanson, R. L. \& Knowler, W. C. Progression to type 2 diabetes characterized by moderate then rapid glucose increases. Diabetes 56, 2054 2061, doi:10.2337/db07-0053 (2007).

140 Tabak, A. G. et al. Trajectories of glycaemia, insulin sensitivity, and insulin secretion before diagnosis of type 2 diabetes: an analysis from the Whitehall II study. Lancet 373, 2215-2221, doi:10.1016/S0140-6736(09)60619-X (2009).

141 Heianza, Y. et al. Longitudinal trajectories of $\mathrm{HbA} 1 \mathrm{c}$ and fasting plasma glucose levels during the development of type 2 diabetes: the Toranomon Hospital Health Management Center Study 7 (TOPICS
7). Diabetes care 35, 1050-1052, doi:10.2337/dc11-1793 (2012).

142 Kahn, S. E. et al. Quantification of the relationship between insulin sensitivity and beta-cell function in human subjects. Evidence for a hyperbolic function. Diabetes 42, 1663-1672 (1993).

143 Utzschneider, K. M. et al. Impact of differences in fasting glucose and glucose tolerance on the hyperbolic relationship between insulin sensitivity and insulin responses. Diabetes care 29, 356-362 (2006).

144 Dankner, R., Chetrit, A., Shanik, M. H., Raz, I. \& Roth, J. Basal-state hyperinsulinemia in healthy normoglycemic adults is predictive of type 2 diabetes over a 24-year followup: a preliminary report. Diabetes care 32, 1464-1466, doi:10.2337/dc09-0153 (2009).

145 Song, B., Scheuner, D., Ron, D., Pennathur, S. \& Kaufman, R. J. Chop deletion reduces oxidative stress, improves beta cell function, and promotes cell survival in multiple mouse models of diabetes. J Clin Invest 118, 3378-3389, doi:10.1172/JCl34587 (2008).

146 Butler, A. E. et al. Beta-cell deficit and increased beta-cell apoptosis in humans with type 2 diabetes. Diabetes 52, 102-110 (2003).

147 Yoon, K. H. et al. Selective beta-cell loss and alpha-cell expansion in patients with type 2 diabetes mellitus in Korea. The Journal of clinical endocrinology and metabolism 88, 2300-2308, doi:10.1210/jc.2002-020735 (2003).

148 Deng, S. et al. Structural and functional abnormalities in the islets isolated from type 2 diabetic subjects. Diabetes 53, 624-632 (2004).

149 Rahier, J., Guiot, Y., Goebbels, R. M., Sempoux, C. \& Henquin, J. C. 
Pancreatic beta-cell mass in European subjects with type 2 diabetes. Diabetes, obesity \& metabolism 10 Suppl 4, 3242 , doi:10.1111/j.14631326.2008.00969.x (2008).

150 Inaishi, J. et al. Effects of Obesity and Diabetes on alpha- and beta-Cell Mass in Surgically Resected Human Pancreas. The Journal of clinical endocrinology and metabolism 101, 2874-2882, doi:10.1210/jc.2016-1374 (2016).

151 Meier, J. J. et al. Functional assessment of pancreatic beta-cell area in humans. Diabetes 58, 1595-1603, doi:10.2337/db08-1611 (2009).

152 Ferrannini, E. et al. The disposal of an oral glucose load in patients with noninsulin-dependent diabetes.

Metabolism: clinical and experimental 37, 79-85 (1988).

153 DeFronzo, R. A., Ferrannini, E. \& Simonson, D. C. Fasting hyperglycemia in non-insulin-dependent diabetes mellitus: contributions of excessive hepatic glucose production and impaired tissue glucose uptake. Metabolism: clinical and experimental 38, 387-395 (1989).

154 Bogardus, C., Lillioja, S. \& Bennett, P. H. Pathogenesis of NIDDM in Pima Indians. Diabetes care 14, 685-690 (1991).

155 Reaven, G. M., Chen, Y. D., Golay, A., Swislocki, A. L. \& Jaspan, J. B. Documentation of hyperglucagonemia throughout the day in nonobese and obese patients with noninsulindependent diabetes mellitus. The Journal of clinical endocrinology and metabolism 64, 106-110, doi:10.1210/jcem-64-1-106 (1987).

156 Henkel, E., Menschikowski, M., Koehler, C., Leonhardt, W. \& Hanefeld, M. Impact of glucagon response on postprandial hyperglycemia in men with impaired glucose tolerance and type 2 diabetes mellitus. Metabolism: clinical and experimental 54, 11681173, doi:10.1016/j.metabol.2005.03.024 (2005).

157 Meier, J. J., Kjems, L. L., Veldhuis, J. D., Lefebvre, P. \& Butler, P. C. Postprandial suppression of glucagon secretion depends on intact pulsatile insulin secretion: further evidence for the intraislet insulin hypothesis. Diabetes 55, 1051-1056 (2006).

158 Exton, J. H. \& Park, C. R. Control of gluconeogenesis in liver. II. Effects of glucagon, catecholamines, and adenosine 3',5'-monophosphate on gluconeogenesis in the perfused rat liver. The Journal of biological chemistry 243, 4189-4196 (1968).

159 Toschi, E. et al. Effect of acute hyperglycemia on insulin secretion in humans. Diabetes 51 Suppl 1, S130-133 (2002).

160 Tersey, S. A. et al. Islet beta-cell endoplasmic reticulum stress precedes the onset of type 1 diabetes in the nonobese diabetic mouse model. Diabetes 61, 818-827, doi:10.2337/db11-1293 (2012).

161 Ravelli, R. B. et al. Destruction of tissue, cells and organelles in type 1 diabetic rats presented at macromolecular resolution. Scientific reports 3, 1804, doi:10.1038/srep01804 (2013).

162 Wilcock, G. K. \& Esiri, M. M. Plaques, tangles and dementia. A quantitative study. Journal of the neurological sciences 56, 343-356 (1982).

163 Terry, R. D. et al. Physical basis of cognitive alterations in Alzheimer's disease: synapse loss is the major correlate of cognitive impairment. Annals of neurology 30, 572-580, doi:10.1002/ana.410300410 (1991).

164 Colvin, M. T. et al. Atomic Resolution Structure of Monomorphic Abeta42 
Amyloid Fibrils. Journal of the American Chemical Society 138, 9663-9674, doi:10.1021/jacs.6b05129 (2016).

165 Walti, M. A. et al. Atomic-resolution structure of a disease-relevant Abeta(142) amyloid fibril. Proceedings of the National Academy of Sciences of the United States of America 113, E49764984, doi:10.1073/pnas.1600749113 (2016).

166 Thinakaran, G. \& Koo, E. H. Amyloid precursor protein trafficking, processing, and function. The Journal of biological chemistry 283, 2961529619, doi:10.1074/jbc.R800019200 (2008).

167 Scheuner, D. et al. Secreted amyloid beta-protein similar to that in the senile plaques of Alzheimer's disease is increased in vivo by the presenilin 1 and 2 and APP mutations linked to familial Alzheimer's disease. Nature medicine 2, 864-870 (1996).

168 Kumar-Singh, S. et al. Mean age-ofonset of familial alzheimer disease caused by presenilin mutations correlates with both increased Abeta42 and decreased Abeta40. Human mutation 27, 686-695, doi:10.1002/humu.20336 (2006).

169 Alzforum. Alzheimer's mutations database,

<http://www.alzforum.org/mutations > (2017).

170 Chen, Y. R. \& Glabe, C. G. Distinct early folding and aggregation properties of Alzheimer amyloid-beta peptides Abeta40 and Abeta42: stable trimer or tetramer formation by Abeta42. The Journal of biological chemistry 281, 24414-24422, doi:10.1074/jbc.M602363200 (2006).

171 Kuperstein, I. et al. Neurotoxicity of Alzheimer's disease Abeta peptides is induced by small changes in the Abeta42 to Abeta40 ratio. The EMBO journal

29,

3408-3420,

doi:10.1038/emboj.2010.211 (2010).

172 Bartolini, M. et al. Kinetic characterization of amyloid-beta 1-42 aggregation with a multimethodological approach. Analytical biochemistry 414, 215-225, doi:10.1016/j.ab.2011.03.020 (2011).

173 Meisl, G. et al. Differences in nucleation behavior underlie the contrasting aggregation kinetics of the Abeta40 and Abeta42 peptides. Proceedings of the National Academy of Sciences of the United States of America 111, 93849389, doi:10.1073/pnas.1401564111 (2014).

174 Gessel, M. M., Bernstein, S., Kemper, M., Teplow, D. B. \& Bowers, M. T. Familial Alzheimer's disease mutations differentially alter amyloid beta-protein oligomerization. ACS chemical neuroscience 3, 909-918, doi:10.1021/cn300050d (2012).

175 Attar, A., Meral, D., Urbanc, B. \& Bitan, $\mathrm{G}$. in Bio-nanoimaging (ed Yuri L. Lyubchenko) 429-442 (Academic Press, 2014).

176 Calabrese, B. et al. Rapid, concurrent alterations in pre- and postsynaptic structure induced by naturally-secreted amyloid-beta protein. Molecular and cellular neurosciences 35, 183-193, doi:10.1016/j.mcn.2007.02.006 (2007).

177 Shankar, G. M. et al. Natural oligomers of the Alzheimer amyloid-beta protein induce reversible synapse loss by modulating an NMDA-type glutamate receptor-dependent signaling pathway. The Journal of neuroscience : the official journal of the Society for Neuroscience 27, 2866-2875, doi:10.1523/JNEUROSCI.4970-06.2007 (2007).

178 Wang, X. et al. Impaired balance of mitochondrial fission and fusion in Alzheimer's disease. The Journal of 
neuroscience : the official journal of the Society for Neuroscience 29, 90909103, doi:10.1523/JNEUROSCI.135709.2009 (2009).

179 Benilova, I., Karran, E. \& De Strooper, B. The toxic Abeta oligomer and Alzheimer's disease: an emperor in need of clothes. Nature neuroscience 15, 349-357, doi:10.1038/nn.3028 (2012).

180 Baker, H. F., Ridley, R. M., Duchen, L. W., Crow, T. J. \& Bruton, C. J. Evidence for the experimental transmission of cerebral beta-amyloidosis to primates. International journal of experimental pathology 74, 441-454 (1993).

181 Ridley, R. M., Baker, H. F., Windle, C. P. \& Cummings, R. M. Very long term studies of the seeding of betaamyloidosis in primates. Journal of neural transmission 113, 1243-1251, doi:10.1007/s00702-005-0385-2 (2006).

182 Frost, B. \& Diamond, M. I. Prion-like mechanisms in neurodegenerative diseases. Nat Rev Neurosci 11, 155-159, doi:10.1038/nrn2786 (2010).

183 Goedert, M., Clavaguera, F. \& Tolnay, M. The propagation of prion-like protein inclusions in neurodegenerative diseases. Trends in neurosciences 33, 317-325,

doi:10.1016/j.tins.2010.04.003 (2010).

184 Jucker, M. \& Walker, L. C. Pathogenic protein seeding in Alzheimer disease and other neurodegenerative disorders. Annals of neurology 70, 532540, doi:10.1002/ana.22615 (2011).

185 Frisoni, G. B. et al. Hippocampal and entorhinal cortex atrophy in frontotemporal dementia and Alzheimer's disease. Neurology 52, 91 100 (1999).

186 Juottonen, K., Laakso, M. P., Partanen, K. \& Soininen, H. Comparative MR analysis of the entorhinal cortex and hippocampus in diagnosing Alzheimer disease. AJNR. American journal of neuroradiology 20, 139-144 (1999).

187 Price, J. L. et al. Neuron number in the entorhinal cortex and CA1 in preclinical Alzheimer disease. Archives of neurology 58, 1395-1402 (2001).

188 Jin, K. et al. Increased hippocampal neurogenesis in Alzheimer's disease. Proceedings of the National Academy of Sciences of the United States of America 101, 343-347, doi:10.1073/pnas.2634794100 (2004).

189 Scheff, S. W., Price, D. A., Schmitt, F. A. \& Mufson, E. J. Hippocampal synaptic loss in early Alzheimer's disease and mild cognitive impairment. Neurobiology of aging 27, 1372-1384, doi:10.1016/j.neurobiolaging.2005.09. 012 (2006).

190 Devanand, D. P. et al. Hippocampal and entorhinal atrophy in mild cognitive impairment: prediction of Alzheimer disease. Neurology 68, 828-836, doi:10.1212/01.wnl.0000256697.20968 .d7 (2007).

191 Henneman, W. J. et al. Hippocampal atrophy rates in Alzheimer disease: added value over whole brain volume measures. Neurology 72, 999-1007, doi:10.1212/01.wnl.0000344568.09360 .31 (2009).

192 Mu, Y. \& Gage, F. H. Adult hippocampal neurogenesis and its role in Alzheimer's disease. Molecular neurodegeneration 6, 85, doi:10.1186/1750-1326-6-85 (2011).

193 Dore, V. et al. Cross-sectional and longitudinal analysis of the relationship between Abeta deposition, cortical thickness, and memory in cognitively unimpaired individuals and in Alzheimer disease. JAMA neurology 70, 903-911,

doi:10.1001/jamaneurol.2013.1062 (2013). 
194 Morris, A. M., Watzky, M. A., Agar, J. N. \& Finke, R. G. Fitting neurological protein aggregation kinetic data via a 2step, minimal/"Ockham's razor" model: the Finke-Watzky mechanism of nucleation followed by autocatalytic surface growth. Biochemistry 47, 24132427, doi:10.1021/bi701899y (2008).

195 Cohen, S. I. et al. Proliferation of amyloid-beta42 aggregates occurs through a secondary nucleation mechanism. Proceedings of the National Academy of Sciences of the United States of America 110, 97589763, doi:10.1073/pnas.1218402110 (2013).

196 Gu, L. \& Guo, Z. Alzheimer's Abeta42 and Abeta40 peptides form interlaced amyloid fibrils. Journal of neurochemistry 126, 305-311, doi:10.1111/jnc.12202 (2013).

197 Hsieh, $H$. et al. AMPAR removal underlies Abeta-induced synaptic depression and dendritic spine loss. Neuron 52, 831-843, doi:10.1016/j.neuron.2006.10.035 (2006).

198 Shrestha, B. R. et al. Amyloid beta peptide adversely affects spine number and motility in hippocampal neurons. Molecular and cellular neurosciences 33, 274-282, doi:10.1016/j.mcn.2006.07.011 (2006).

199 Leshchyns'ka, l. et al. Abeta-dependent reduction of NCAM2-mediated synaptic adhesion contributes to synapse loss in Alzheimer's disease. Nature communications 6, 8836, doi:10.1038/ncomms9836 (2015).

200 Gamblin, T. C. et al. Caspase cleavage of tau: linking amyloid and neurofibrillary tangles in Alzheimer's disease. Proceedings of the National Academy of Sciences of the United States of America 100, 10032-10037, doi:10.1073/pnas.1630428100 (2003).
201 Ittner, L. M. \& Gotz, J. Amyloid-beta and tau--a toxic pas de deux in Alzheimer's disease. Nat Rev Neurosci 12, 65-72, doi:10.1038/nrn2967 (2011).

202 Pritchard, S. M., Dolan, P. J., Vitkus, A. \& Johnson, G. V. The toxicity of tau in Alzheimer disease: turnover, targets and potential therapeutics. J Cell Mol Med 15, 1621-1635, doi:10.1111/j.1582-4934.2011.01273.x (2011).

203 Patterson, K. R. et al. Characterization of prefibrillar Tau oligomers in vitro and in Alzheimer disease. The Journal of biological chemistry 286, 23063-23076, doi:10.1074/jbc.M111.237974 (2011).

204 Paresce, D. M., Ghosh, R. N. \& Maxfield, F. R. Microglial cells internalize aggregates of the Alzheimer's disease amyloid beta-protein via a scavenger receptor. Neuron 17, 553-565 (1996).

205 El Khoury, J. B. et al. CD36 mediates the innate host response to beta-amyloid. The Journal of experimental medicine 197, 1657-1666, doi:10.1084/jem.20021546 (2003).

206 Villemagne, V. L. et al. Amyloid beta deposition, neurodegeneration, and cognitive decline in sporadic Alzheimer's disease: a prospective cohort study. The Lancet. Neurology 12, 357-367, doi:10.1016/S14744422(13)70044-9 (2013).

207 Nie, O., Du, X. G. \& Geng, M. Y. Small molecule inhibitors of amyloid beta peptide aggregation as a potential therapeutic strategy for Alzheimer's disease. Acta Pharmacol Sin 32, 545551, doi:10.1038/aps.2011.14 (2011).

208 Belluti, F., Rampa, A., Gobbi, S. \& Bisi, A. Small-molecule inhibitors/modulators of amyloid-beta peptide aggregation and toxicity for the treatment of Alzheimer's disease: a patent review (2010 - 2012). Expert opinion on therapeutic patents 23,581 . 
596,

doi:10.1517/13543776.2013.772983

(2013).

209 Doig, A. J. \& Derreumaux, P. Inhibition of protein aggregation and amyloid formation by small molecules. Current opinion in structural biology $30,50-56$, doi:10.1016/j.sbi.2014.12.004 (2015).

210 Cohen, S. I. et al. A molecular chaperone breaks the catalytic cycle that generates toxic Abeta oligomers. Nature structural \& molecular biology 22, 207-213, doi:10.1038/nsmb.2971 (2015).

211 Damier, P., Hirsch, E. C., Agid, Y. \& Graybiel, A. M. The substantia nigra of the human brain. II. Patterns of loss of dopamine-containing neurons in Parkinson's disease. Brain : a journal of neurology 122 ( Pt 8), 1437-1448 (1999).

212 Lewis, S. J. \& Barker, R. A. Understanding the dopaminergic deficits in Parkinson's disease: insights into disease heterogeneity. Journal of clinical neuroscience : official journal of the Neurosurgical Society of Australasia 16 ,

620-625, doi:10.1016/j.jocn.2008.08.020 (2009).

213 Hughes, A. J., Daniel, S. E., Kilford, L. \& Lees, A. J. Accuracy of clinical diagnosis of idiopathic Parkinson's disease: a clinico-pathological study of 100 cases. Journal of neurology, neurosurgery, and psychiatry 55, 181-184 (1992).

214 Spillantini, M. G. et al. Alpha-synuclein in Lewy bodies. Nature 388, 839-840, doi:10.1038/42166 (1997).

215 Spillantini, M. G., Crowther, R. A., Jakes, R., Hasegawa, M. \& Goedert, M. alphaSynuclein in filamentous inclusions of Lewy bodies from Parkinson's disease and dementia with lewy bodies. Proceedings of the National Academy of Sciences of the United States of America 95, 6469-6473 (1998).
216 Gai, W. P. et al. In situ and in vitro study of colocalization and segregation of alpha-synuclein, ubiquitin, and lipids in Lewy bodies. Experimental neurology 166,

324-333,

doi:10.1006/exnr.2000.7527 (2000).

217 McNaught, K. S., Shashidharan, P., Perl, D. P., Jenner, P. \& Olanow, C. W. Aggresome-related biogenesis of Lewy bodies. The European journal of neuroscience 16, 2136-2148 (2002).

218 Kanazawa, T. et al. Three-layered structure shared between Lewy bodies and lewy neurites-three-dimensional reconstruction of triple-labeled sections. Brain pathology 18, 415-422, doi:10.1111/j.1750-3639.2008.00140.x (2008).

219 Gomperts, S. N. Lewy Body Dementias: Dementia With Lewy Bodies and Parkinson Disease Dementia. Continuum 22, 435-463, doi:10.1212/CON.0000000000000309 (2016).

220 Polymeropoulos, M. H. et al. Mutation in the alpha-synuclein gene identified in families with Parkinson's disease. Science 276, 2045-2047 (1997).

221 Kruger, R. et al. Ala30Pro mutation in the gene encoding alpha-synuclein in Parkinson's disease. Nature genetics 18, 106-108, doi:10.1038/ng0298-106 (1998).

222 Zarranz, J. J. et al. The new mutation, E46K, of alpha-synuclein causes Parkinson and Lewy body dementia. Annals of neurology 55, 164-173, doi:10.1002/ana.10795 (2004).

223 Singleton, A. B. et al. alpha-Synuclein locus triplication causes Parkinson's disease. Science 302, 841, doi:10.1126/science.1090278 (2003).

224 Chartier-Harlin, M. C. et al. Alphasynuclein locus duplication as a cause of familial Parkinson's disease. Lancet 
364, 1167-1169, doi:10.1016/S01406736(04)17103-1 (2004).

225 Ibanez, P. et al. Causal relation between alpha-synuclein gene duplication and familial Parkinson's disease. Lancet 364, 1169-1171, doi:10.1016/S01406736(04)17104-3 (2004).

226 Fuchs, J. et al. Phenotypic variation in a large Swedish pedigree due to SNCA duplication and triplication. Neurology 68,

916-922,

doi:10.1212/01.wnl.0000254458.17630 .c5 (2007).

227 Kitada, T. et al. Mutations in the parkin gene cause autosomal recessive juvenile parkinsonism. Nature 392, 605608, doi:10.1038/33416 (1998).

228 Valente, E. M. et al. Hereditary earlyonset Parkinson's disease caused by mutations in PINK1. Science 304, 11581160, doi:10.1126/science.1096284 (2004).

229 Bonifati, V. et al. Mutations in the DJ-1 gene associated with autosomal recessive early-onset parkinsonism. Science 299, 256-259, doi:10.1126/science.1077209 (2003).

230 Farrer, M. et al. alpha-Synuclein gene haplotypes are associated with Parkinson's disease. Human molecular genetics 10, 1847-1851 (2001).

231 Pals, P. et al. alpha-Synuclein promoter confers susceptibility to Parkinson's disease. Annals of neurology 56, 591595, doi:10.1002/ana.20268 (2004).

232 Mellick, G. D., Maraganore, D. M. \& Silburn, P. A. Australian data and metaanalysis lend support for alphasynuclein (NACP-Rep1) as a risk factor for Parkinson's disease. Neuroscience letters 375, 112-116, doi:10.1016/j.neulet.2004.10.078 (2005).

233 Mueller, J. C. et al. Multiple regions of alpha-synuclein are associated with Parkinson's disease. Annals of neurology

57, $535-541$ doi:10.1002/ana.20438 (2005).

234 Maraganore, D. M. et al. Collaborative analysis of alpha-synuclein gene promoter variability and Parkinson disease. Jama 296, 661-670, doi:10.1001/jama.296.6.661 (2006).

235 Mizuta, I. et al. Multiple candidate gene analysis identifies alpha-synuclein as a susceptibility gene for sporadic Parkinson's disease. Human molecular genetics 15, 1151-1158, doi:10.1093/hmg/ddl030 (2006).

236 Satake, W. et al. Genome-wide association study identifies common variants at four loci as genetic risk factors for Parkinson's disease. Nature genetics 41, 1303-1307, doi:10.1038/ng.485 (2009).

237 Simon-Sanchez, J. et al. Genome-wide association study reveals genetic risk underlying Parkinson's disease. Nature genetics 41, 1308-1312, doi:10.1038/ng.487 (2009).

238 van den Berge, S. A. et al. The proliferative capacity of the subventricular zone is maintained in the parkinsonian brain. Brain : a journal of neurology 134, 3249-3263, doi:10.1093/brain/awr256 (2011).

239 Ernst, A. et al. Neurogenesis in the striatum of the adult human brain. Cell 156, 1072-1083, doi:10.1016/j.cell.2014.01.044 (2014).

240 Hoglinger, G. U. et al. Dopamine depletion impairs precursor cell proliferation in Parkinson disease. Nature neuroscience 7, 726-735, doi:10.1038/nn1265 (2004).

241 Freundlieb, N. et al. Dopaminergic substantia nigra neurons project topographically organized to the subventricular zone and stimulate precursor cell proliferation in aged primates. The Journal of neuroscience : the official journal of the Society for 
Neuroscience 26, 2321-2325, doi:10.1523/JNEUROSCI.4859-05.2006 (2006).

242 Hedlund, E. et al. Dopamine Receptor Antagonists Enhance Proliferation and Neurogenesis of Midbrain Lmx1aexpressing Progenitors. Scientific reports 6, 26448, doi:10.1038/srep26448 (2016).

243 Kempster, P. A., Gibb, W. R., Stern, G. M. \& Lees, A. J. Asymmetry of substantia nigra neuronal loss in Parkinson's disease and its relevance to the mechanism of levodopa related motor fluctuations. Journal of neurology, neurosurgery, and psychiatry 52, 72-76 (1989).

244 Djaldetti, R., Ziv, I. \& Melamed, E. The mystery of motor asymmetry in Parkinson's disease. The Lancet. Neurology 5, 796-802, doi:10.1016/S1474-4422(06)70549-X (2006).

245 Lucking, C. B. et al. Association between early-onset Parkinson's disease and mutations in the parkin gene. The New England journal of medicine 342, 1560-1567, doi:10.1056/NEJM200005253422103 (2000).

246 Bonifati, V. et al. Early-onset parkinsonism associated with PINK1 mutations: frequency, genotypes, and phenotypes. Neurology 65, 87-95, doi:10.1212/01.wnl.0000167546.39375 .82 (2005).

247 Conway, K. A., Harper, J. D. \& Lansbury, P. T. Accelerated in vitro fibril formation by a mutant alpha-synuclein linked to early-onset Parkinson disease. Nature medicine 4, 1318-1320, doi:10.1038/3311 (1998).

248 Giasson, B. I. et al. Neuronal alphasynucleinopathy with severe movement disorder in mice expressing A53T human alpha-synuclein. Neuron 34, 521-533 (2002).

249 Lashuel, H. A. et al. Alpha-synuclein, especially the Parkinson's diseaseassociated mutants, forms pore-like annular and tubular protofibrils. Journal of molecular biology 322, 1089-1102 (2002).

250 Choi, W. et al. Mutation E46K increases phospholipid binding and assembly into filaments of human alphasynuclein. FEBS letters 576, 363-368, doi:10.1016/j.febslet.2004.09.038 (2004).

251 Bertoncini, C. W., Fernandez, C. O., Griesinger, C., Jovin, T. M. \& Zweckstetter, M. Familial mutants of alpha-synuclein with increased neurotoxicity have a destabilized conformation. The Journal of biological chemistry 280, 30649-30652, doi:10.1074/jbc.C500288200 (2005).

252 Yonetani, M. et al. Conversion of wildtype alpha-synuclein into mutant-type fibrils and its propagation in the presence of A30P mutant. The Journal of biological chemistry 284, 7940-7950, doi:10.1074/jbc.M807482200 (2009).

253 Kirik, D. et al. Nigrostriatal alphasynucleinopathy induced by viral vector-mediated overexpression of human alpha-synuclein: a new primate model of Parkinson's disease. Proceedings of the National Academy of Sciences of the United States of America 100, 2884-2889, doi:10.1073/pnas.0536383100 (2003).

254 Farrer, M. et al. Comparison of kindreds with parkinsonism and alpha-synuclein genomic multiplications. Annals of neurology 55 , 174-179, doi:10.1002/ana.10846 (2004).

255 Miller, D. W. et al. Alpha-synuclein in blood and brain from familial Parkinson disease with SNCA locus triplication. Neurology 62, 1835-1838 (2004). 
256 Yedlapudi, D., Joshi, G. S., Luo, D., Todi, S. V. \& Dutta, A. K. Inhibition of alpha-synuclein aggregation by multifunctional dopamine agonists assessed by a novel in vitro assay and an in vivo Drosophila synucleinopathy model. Scientific reports 6, 38510, doi:10.1038/srep38510 (2016).

257 Liu, C. W. et al. A precipitating role for truncated alpha-synuclein and the proteasome in alpha-synuclein aggregation: implications for pathogenesis of Parkinson disease. The Journal of biological chemistry 280, 22670-22678,

doi:10.1074/jbc.M501508200 (2005).

258 Chen, L., Thiruchelvam, M. J., Madura, K. \& Richfield, E. K. Proteasome dysfunction in aged human alphasynuclein transgenic mice. Neurobiology of disease 23, 120-126, doi:10.1016/j.nbd.2006.02.004 (2006).

259 Chu, Y., Dodiya, H., Aebischer, P., Olanow, C. W. \& Kordower, J. H. Alterations in lysosomal and proteasomal markers in Parkinson's disease: relationship to alpha-synuclein inclusions. Neurobiology of disease 35, 385-398, doi:10.1016/j.nbd.2009.05.023 (2009).

$260 \mathrm{Li}, \mathrm{W}$. et al. Aggregation promoting Cterminal truncation of alpha-synuclein is a normal cellular process and is enhanced by the familial Parkinson's disease-linked mutations. Proceedings of the National Academy of Sciences of the United States of America 102, 21622167, doi:10.1073/pnas.0406976102 (2005).

261 Crowther, R. A., Jakes, R., Spillantini, M. G. \& Goedert, M. Synthetic filaments assembled from C-terminally truncated alpha-synuclein. FEBS letters 436, 309312 (1998).

262 Tofaris, G. K. et al. Pathological changes in dopaminergic nerve cells of the substantia nigra and olfactory bulb in mice transgenic for truncated human alpha-synuclein(1-120): implications for Lewy body disorders. The Journal of neuroscience : the official journal of the Society for Neuroscience 26, 39423950, doi:10.1523/JNEUROSCI.496505.2006 (2006).

263 Murray, I. V. et al. Role of alphasynuclein carboxy-terminus on fibril formation in vitro. Biochemistry 42, 8530-8540, doi:10.1021/bi027363r (2003).

264 Ulusoy, A., Febbraro, F., Jensen, P. H., Kirik, D. \& Romero-Ramos, M. Coexpression of C-terminal truncated alpha-synuclein enhances full-length alpha-synuclein-induced pathology. The European journal of neuroscience 32, 409-422, doi:10.1111/j.14609568.2010.07284.x (2010).

265 Kim, J., Harada, R., Kobayashi, M., Kobayashi, N. \& Sode, K. The inhibitory effect of pyrroloquinoline quinone on the amyloid formation and cytotoxicity of truncated alpha-synuclein. Molecular neurodegeneration $5, \quad 20$, doi:10.1186/1750-1326-5-20 (2010).

266 Lo Bianco, C., Ridet, J. L., Schneider, B. L., Deglon, N. \& Aebischer, P. alpha Synucleinopathy and selective dopaminergic neuron loss in a rat lentiviral-based model of Parkinson's disease. Proceedings of the National Academy of Sciences of the United States of America 99, 10813-10818, doi:10.1073/pnas.152339799 (2002).

267 Lashuel, H. A., Hartley, D., Petre, B. M., Walz, T. \& Lansbury, P. T., Jr. Neurodegenerative disease: amyloid pores from pathogenic mutations. Nature 418, 291, doi:10.1038/418291a (2002).

268 Winner, B. et al. In vivo demonstration that alpha-synuclein oligomers are toxic. Proceedings of the National 
Academy of Sciences of the United States of America 108, 4194-4199, doi:10.1073/pnas.1100976108 (2011).

269 Greffard, S. et al. A stable proportion of Lewy body bearing neurons in the substantia nigra suggests a model in which the Lewy body causes neuronal death. Neurobiology of aging 31, 99103,

doi:10.1016/j.neurobiolaging.2008.03. 015 (2010).

270 Bedford, L. et al. Depletion of $26 \mathrm{~S}$ proteasomes in mouse brain neurons causes neurodegeneration and Lewylike inclusions resembling human pale bodies. The Journal of neuroscience : the official journal of the Society for Neuroscience 28, 8189-8198, doi:10.1523/JNEUROSCI.2218-08.2008 (2008).

271 Devi, L., Raghavendran, V., Prabhu, B. M., Avadhani, N. G. \& Anandatheerthavarada, $\quad H$. K. Mitochondrial import and accumulation of alpha-synuclein impair complex I in human dopaminergic neuronal cultures and Parkinson disease brain. The Journal of biological chemistry 283, 9089-9100, doi:10.1074/jbc.M710012200 (2008).

272 Liu, G. et al. alpha-Synuclein is differentially expressed in mitochondria from different rat brain regions and dose-dependently down-regulates complex I activity. Neuroscience letters 454,

187-192,

doi:10.1016/j.neulet.2009.02.056 (2009).

273 Michelini, L. G., Benevento, C. E., Rossato, F. A., Siqueira-Santos, E. S. \& Castilho, R. F. Effects of partial inhibition of respiratory complex I on $\mathrm{H} 2 \mathrm{O} 2$ production by isolated brain mitochondria in different respiratory states. Neurochemical research 39,
2419-2430, doi:10.1007/s11064-0141446-4 (2014).

274 Conway, K. A., Rochet, J. C., Bieganski, R. M. \& Lansbury, P. T., Jr. Kinetic stabilization of the alpha-synuclein protofibril by a dopamine-alphasynuclein adduct. Science 294, 13461349, doi:10.1126/science.1063522 (2001).

$275 \mathrm{Xu}, \mathrm{J}$. et al. Dopamine-dependent neurotoxicity of alpha-synuclein: a mechanism for selective neurodegeneration in Parkinson disease. Nature medicine 8, 600-606, doi:10.1038/nm0602-600 (2002).

276 Pham, C. L. et al. Dopamine and the dopamine oxidation product 5,6dihydroxylindole promote distinct onpathway and off-pathway aggregation of alpha-synuclein in a pH-dependent manner. Journal of molecular biology 387,

771-785, doi:10.1016/j.jmb.2009.02.007 (2009).

277 Rekas, A. et al. The structure of dopamine induced alpha-synuclein oligomers. European biophysics journal : EBJ 39, 1407-1419, doi:10.1007/s00249-010-0595-x (2010).

278 Palacino, J. J. et al. Mitochondrial dysfunction and oxidative damage in parkin-deficient mice. The Journal of biological chemistry 279, 18614-18622, doi:10.1074/jbc.M401135200 (2004).

279 Gautier, C. A., Kitada, T. \& Shen, J. Loss of PINK1 causes mitochondrial functional defects and increased sensitivity to oxidative stress. Proceedings of the National Academy of Sciences of the United States of America 105, 11364-11369, doi:10.1073/pnas.0802076105 (2008).

280 Zhang, L. et al. Mitochondrial localization of the Parkinson's disease related protein DJ-1: implications for pathogenesis. Human molecular 
genetics

14,

2063-2073

doi:10.1093/hmg/ddi211 (2005).

281 Andres-Mateos, E. et al. DJ-1 gene deletion reveals that $\mathrm{DJ}-1$ is an atypical peroxiredoxin-like peroxidase. Proceedings of the National Academy of Sciences of the United States of America 104, 14807-14812, doi:10.1073/pnas.0703219104 (2007).

282 Irrcher, I. et al. Loss of the Parkinson's disease-linked gene DJ-1 perturbs mitochondrial dynamics. Human molecular genetics 19, 3734-3746, doi:10.1093/hmg/ddq288 (2010).

283 Schapira, A. H. et al. Mitochondrial complex I deficiency in Parkinson's disease. Lancet 1, 1269 (1989).

284 Schapira, A. H. et al. Anatomic and disease specificity of NADH CoQ1 reductase (complex I) deficiency in Parkinson's disease. Journal of neurochemistry 55, 2142-2145 (1990).

285 Davis, G. C. et al. Chronic Parkinsonism secondary to intravenous injection of meperidine analogues. Psychiatry research 1, 249-254 (1979).

286 Langston, J. W., Ballard, P., Tetrud, J. W. \& Irwin, I. Chronic Parkinsonism in humans due to a product of meperidine-analog synthesis. Science 219, 979-980 (1983).

287 Sechi, G. P. et al. Acute and persistent parkinsonism after use of diquat. Neurology 42, 261-263 (1992).

288 Betarbet, R. et al. Chronic systemic pesticide exposure reproduces features of Parkinson's disease. Nature neuroscience 3, 1301-1306, doi:10.1038/81834 (2000).

289 Tanner, C. M. et al. Rotenone, paraquat, and Parkinson's disease. Environmental health perspectives 119, 866-872, doi:10.1289/ehp.1002839(2011).

290 Hantraye, P. et al. Stable parkinsonian syndrome and uneven loss of striatal dopamine fibres following chronic
MPTP administration in baboons. Neuroscience 53, 169-178 (1993).

291 Vingerhoets, F. J. et al. Positron emission tomographic evidence for progression of human MPTP-induced dopaminergic lesions. Annals of neurology 36, 765-770, doi:10.1002/ana.410360513 (1994).

292 Dauer, W. et al. Resistance of alpha synuclein null mice to the parkinsonian neurotoxin MPTP. Proceedings of the National Academy of Sciences of the United States of America 99, 1452414529, doi:10.1073/pnas.172514599 (2002).

293 Braak, H., de Vos, R. A., Bohl, J. \& Del Tredici, K. Gastric alpha-synuclein immunoreactive inclusions in Meissner's and Auerbach's plexuses in cases staged for Parkinson's diseaserelated brain pathology. Neuroscience letters 396. $67-72$ doi:10.1016/j.neulet.2005.11.012 (2006).

294 Pan-Montojo, F. et al. Progression of Parkinson's disease pathology is reproduced by intragastric administration of rotenone in mice. PLoS One 5, e8762, doi:10.1371/journal.pone.0008762 (2010).

295 Jin, $H$. et al. Mitochondria-targeted antioxidants for treatment of Parkinson's disease: preclinical and clinical outcomes. Biochimica et biophysica acta 1842, 1282-1294, doi:10.1016/j.bbadis.2013.09.007 (2014).

296 Snow, B. J. et al. A double-blind, placebo-controlled study to assess the mitochondria-targeted antioxidant Mito $\mathrm{Q}$ as a disease-modifying therapy in Parkinson's disease. Movement disorders : official journal of the Movement Disorder Society 25, 1670 1674, doi:10.1002/mds.23148 (2010). 
297 Hamilton, W. D., Axelrod, R. \& Tanese, R. Sexual reproduction as an adaptation to resist parasites (a review). Proceedings of the National Academy of Sciences of the United States of America 87, 3566-3573 (1990).

298 Morran, L. T., Schmidt, O. G., Gelarden, I. A., Parrish, R. C., 2nd \& Lively, C. M. Running with the Red Queen: hostparasite coevolution selects for biparental sex. Science 333, 216-218, doi:10.1126/science.1206360 (2011).

299 Franceschi, C., Garagnani, P., Vitale, G., Capri, M. \& Salvioli, S. Inflammaging and 'Garb-aging'. Trends in endocrinology and metabolism: TEM 28, 199-212, doi:10.1016/j.tem.2016.09.005 (2017).

300 Egger, G. \& Dixon, J. Beyond obesity and lifestyle: a review of 21 st century chronic disease determinants. BioMed research international 2014, 731685, doi:10.1155/2014/731685 (2014).

301 Freitas, A. A. \& de Magalhaes, J. P. A review and appraisal of the DNA damage theory of ageing. Mutation research 728, 12-22, doi:10.1016/j.mrrev.2011.05.001 (2011).

302 Harman, D. Free radical theory of aging: an update: increasing the functional life span. Annals of the New York Academy of Sciences 1067, 10-21, doi:10.1196/annals.1354.003 (2006).

303 Burger, O., Baudisch, A. \& Vaupel, J. W. Human mortality improvement in evolutionary context. Proceedings of the National Academy of Sciences of the United States of America 109, 18210-18214, doi:10.1073/pnas.1215627109 (2012).

304 Gurven, M. \& Kaplan, H. Longevity Among Hunter- Gatherers: A CrossCultural Examination. Population and Development Review 33, 321-365, doi:10.1111/j.1728-4457.2007.00171.x (2007).

305 Palasi, A. et al. Differentiated clinical presentation of early and late-onset Alzheimer's disease: is 65 years of age providing a reliable threshold? Journal of neurology 262, 1238-1246, doi:10.1007/s00415-015-7698-3 (2015).

306 Ferguson, L. W., Rajput, A. H. \& Rajput, A. Early-onset vs. Late-onset Parkinson's disease: A Clinical-pathological Study. The Canadian journal of neurological sciences. Le journal canadien des sciences neurologiques 43, 113-119, doi:10.1017/cjn.2015.244 (2016).

307 Williams, G. C. Pleiotropy, Natural Selection, and the Evolution of Senescence. Evolution 11, 398-411, doi:10.2307/2406060 (1957).

308 Berzlanovich, A. M. et al. Do centenarians die healthy? An autopsy study. The journals of gerontology. Series A, Biological sciences and medical sciences 60, 862-865 (2005). 